\title{
Proliferative and Non-Proliferative Lesions of the Rat and Mouse Soft Tissue, Skeletal Muscle and Mesothelium
}

\author{
Peter Greaves 1 , Luc Chouinard 2 , Heinrich Ernst ${ }^{3}$, Lars Mecklenburg ${ }^{4}$, Ingrid M. Pruimboom-Brees 5 , \\ Matthias Rinke ${ }^{6}$, Susanne Rittinghausen ${ }^{7}$, Stéphane Thibault $^{8}$, Jasmin von Erichsen $^{9}$, and Toshinori Yoshida ${ }^{10}$ \\ ${ }^{1}$ University of Leicester, Department of Cancer Studies, Leicester, UK \\ ${ }^{2}$ Charles River Laboratories, Quebec, Canada \\ ${ }^{3}$ Fraunhofer Institute for Toxicology and Experimental Medicine ITEM, Hannover, Germany \\ ${ }^{4}$ European Advanced Risk Assessor, Hamburg, Germany \\ 5 Novartis Pharma AG, Basel, Switzerland \\ ${ }^{6}$ Bayer Pharma AG, Wuppertal, Germany \\ ${ }^{7}$ Fraunhofer Institute for Toxicology and Experimental Medicine ITEM, Hannover, Germany \\ ${ }^{8}$ Pfizer Inc, California, USA \\ ${ }^{9}$ Nycomed: a Takeda Company, Barsbuettel, Germany \\ 10 The Institute of Environmental Toxicology, Ibaraki, Japan
}

\begin{abstract}
The INHAND Project (International Harmonization of Nomenclature and Diagnostic Criteria for Lesions in Rats and Mice) is a joint initiative of the Societies of Toxicologic Pathology from Europe (ESTP), Great Britain (BSTP), Japan (JSTP), and North America (STP) to develop an internationally accepted nomenclature for proliferative and nonproliferative lesions in laboratory animals. The purpose of this publication is to provide a standardized nomenclature for classifying lesions observed in the soft tissues including skeletal muscle as well as the mesothelium of rats and mice. The standardized nomenclature of lesions presented in this document is also available electronically on the Internet (http://www.goreni.org/). Sources of material included histopathology databases from government, academia, and industrial laboratories throughout the world. Content includes spontaneous developmental and aging lesions as well as those induced by exposure to test materials. A widely accepted and utilized international harmonization of nomenclature for lesions in soft tissues, skeletal muscle and mesothelium in laboratory animals will decrease confusion among regulatory and scientific research organizations in different countries and provide a common language to increase and enrich international exchanges of information among toxicologists and pathologists. (DOI: 10.1293/tox.26.1S; J Toxicol Pathol 2013; 26: 1S-26S)
\end{abstract}

Keywords: soft tissues; skeletal muscle; mesotheium; preclinical safety—assessment/risk management; rat pathology; mouse pathology.

\section{INTRODUCTION}

The INHAND Project (International Harmonization of Nomenclature and Diagnostic Criteria for Lesions in Rats and Mice) is a joint initiative of the Societies of Toxicologic Pathology from Europe (ESTP), Great Britain (BSTP), Japan (JSTP) and North America (STP) to develop an internationally-accepted nomenclature for proliferative and non-proliferative lesions in laboratory animals. The purpose of this publication is to provide a standardized nomenclature for classifying proliferative

Address correspondence to: Peter Greaves, MBChB FRCPath, University of Leicester, Department of Cancer Studies, Robert Kilpatrick Clinical Sciences Building, Leicester Royal Infirmary, Leicester, LE2 7LX, United Kingdom. e-mail: pg29@1e.ac.uk

(C2013 The Japanese Society of Toxicologic Pathology

This is an open-access article distributed under the terms of the Creative Commons Attribution Non-Commercial No Derivatives (by-nc-nd) License $<$ http://creativecommons.org/licenses/by-nc-nd/3.0/>. and non-proliferative lesions observed in soft tissues of laboratory rats and mice. Standardized nomenclature of proliferative and non-proliferative lesions of the soft tissues of both rats and mice has been previously published by the STP (Greaves et al. 1992; Greaves and Seely 1996; Greaves et al. 2000). These were subject to extensive reviews and comments by members of STP and were used as the basis for the WHO - International Agency for Research on Cancer classification of tumors in mice and rats (Carlton et al. 1992; Ernst et al. 2001). These STP publications have been used for this current classification. The standardized nomenclature of lesions presented here is also available electronically at the goRENI website (www.goreni. org). This document follows a similar approach to these previous publications.

The basic principles for recording microscopic changes in toxicity studies have been recently summarized (Mann et al. 2012). In these studies microscopic observations should be recorded in a consistent and objective manner. Descriptive rather 
than diagnostic terminology is advisable in order to avoid misleading comparisons with particular diseases.

The conventional view of the soft tissues is one of a cellular component comprising fibroblasts, fat containing cells, specialized skeletal muscle fibers, a matrix of ground substance and various structural proteins including collagen and elastic fibers. These are accompanied by blood vessels and mobile bone-marrow derived cells such as lymphocytes, granular leukocytes and macrophages. This simple concept must now be modified since the discovery of mesenchymal stem cells and their important contribution to tissue homeostasis (Valtieri and Sorrentino 2008). These cells are undifferentiated multipotential cells which reside primarily in the bone marrow but also in other sites including adipose tissue and skeletal muscle (Liu et al. 2009). They are now believed to be important in the functional repair of damaged tissues. Moreover, they have been found to have a central role in the pathogenesis and progression of neoplasia as part of the non-malignant supporting stroma (Valtieri and Sorrentino 2008).

For convenience, mesothelial lesions are also reviewed in this document. Mesothelial cells are derived from the mesoderm but express many epithelial characteristics. They do not regenerate in the same way as epithelial cells although the exact mechanisms involved following injury remain uncertain (Mutsaers et al. 2007). Lesions of the synovium are discussed under the INHAND classification of lesions of the skeletal system.

The pathological features of both spontaneous and induced conditions of soft tissues are similar among different laboratory rodent species as well as humans. Hence, the basic classification developed for mesenchymal lesions can be used for all species, although the range of soft tissue neoplasms described in rodents is far less than those characterized in humans. Nevertheless unusual types of mesenchymal neoplasms are encountered that do not fit into the usual classification scheme.

Careful recording of the nature, intensity and duration of the inflammatory response of the soft tissues to implanted or injected substances is important in the assessment of the local tolerability of agents intended for contact with human tissues. The chemical and physical properties of injected chemicals or vaccines and their adjuvants as well as size, shape and surface texture of implanted biomaterials may modify the histological features and temporal pattern of the inflammatory and reparative responses (Williams 1987; Anderson and Langone 1999; Verdier et al. 2005; Dincer et al. 2006).

\section{MORPHOLOGY}

Non-proliferative lesions
Soft tissues
- Infiltrate, inflammatory cell
- Inflammation
- Fibrosis
- Fibroplasia
- Necrosis
- Mineralization
- Metaplasia
- Amyloid
Adipose tissues
- Infiltrate, inflammatory cell
- Inflammation
- Inflammation, lipogranulomatous
- Necrosis
- Atrophy
- Hyperplasia

\section{Smooth muscle}

The distribution of lesions of smooth muscle generally parallels the normal distribution of smooth muscle in the body so that lesions occur mostly in the female genital tract, the gastrointestinal tract and skin but only rarely in deep soft tissue. However, it has been shown that adipose tissue may have an important paracrine function in smooth muscle cell proliferation in blood vessels (Miao and Li 2012). In soft tissues, particularly in inflammatory processes, smooth muscle cells may be difficult to distinguish from myofibroblasts. They both express smooth muscle actin but smooth muscle cells usually contain desmin (Kempson et al. 2001).

- Hyperplasia, smooth muscle

\section{Skeletal muscle}

Whilst skeletal muscle contains a similar range of connective tissue elements as the other soft tissues, its bulk is predominantly composed of highly specialized skeletal muscle cells or fibers (myocytes). These cells form a syncytium by fusion of fetal myoblasts to produce a muscle fiber whose length is often many thousand times greater than its diameter. Although the principles of pathological changes are similar in muscle to other tissues of the body, its unusual cellular structure and its contractile nature give rise to a constellation of pathological changes that need to be considered separately. The general system of nomenclature of rodent skeletal muscle fiber types is based on the adenosine triphosphatase (ATPase) reaction (Brooke and Kaiser 1970; Brooke et al. 1971). When this reaction is performed at $\mathrm{pH} 9.4$, type I or slow twitch fibers show low myofibrillar ATPase activity. Type II or fast twitch fibers show greater ATPase reactivity and can be divided into type IIA, IIB and IIC on the basis of inhibition of the reaction at lower values of $\mathrm{pH}$. Thus, in the rat type IIA fibers are inhibited at $\mathrm{pH} 4.5$, type IIB at $\mathrm{pH} 4.3$ and type IIC at $\mathrm{pH}$ 3.9. Immunocytochemical techniques based on the fast and slow isoforms of myosin have also been used and correlate reasonably well with fiber type analysis from the standard ATPase method and are applicable to fixed material (Behan et al. 2002; Westwood et al. 2005).

This heterogeneity as well as the fact that muscle represents nearly $40 \%$ of body mass has to be considered in the selection of muscle sampling for histopathological examination. Over 
recent years study of the muscle damage produced in rodents by lipid regulating drugs notably the fibrates and statins have shown that muscle fiber types vary in their sensitivity to xenobiotics (Schaefer et al. 2004; Westwood et al. 2005; De Souza et al. 2006; Okada et al. 2007; Faiola et al. 2008; Westwood et al. 2008; Okada et al. 2009). It is important therefore to include both type 1 and type II fibers for histological assessment. For example the soleus represents a type I-predominant skeletal muscle whereas type II-predominant skeletal muscles are represented by the quadriceps and extensor digitorum longus.

- Infiltrate, inflammatory cell

- Necrosis

- Inflammation

- Hypertrophy

- Atrophy

- Degeneration

- Vacuolation

- Mineralization

Mesothelium

- Hyperplasia

\section{Neoplastic proliferative lesions}

One diagnostic challenge in the assessment of soft tissue pathology is making a distinction between reactive, but selflimiting conditions and neoplastic lesions of mesenchymal cells. Soft tissue tumors are classified according to the adult tissue they resemble. However, they most probably develop from pluripotential mesenchymal cells that are able to differentiate in one or more different directions. For this reason a close histogenetic relationship exists between soft tissue neoplasms and bone tumors (Hajdu 1986). It explains why mixed differentiation patterns occur among soft tissue sarcomas such as reported in some transgenic mouse models (Floyd et al. 2002).

Mesenchymal tumors are relatively uncommon spontaneous lesions in conventional strains of rats and mice, although their incidence in aged untreated animals may vary from less than 1\% to over 5\% (Greaves and Faccini 1981; Poteracki and Walsh 1998; Eiben 2001; Haines et al. 2001; Dinse et al. 2010). The most common malignant phenotype that develops spontaneously is usually fibrosarcoma or its pleomorphic variant (malignant fibrous histiocytoma).

Sarcomas can also be induced in rodents by injection of oncogenic viruses and carcinogens such as 7,12-dimethylbenz $[a]$ anthracene as well as repeated injection of a diverse range of non-genotoxic chemicals (Chesterman et al. 1966; Grasso and Goldberg 1966 a, b; Hooson et al. 1973; Taguchi et al. 2006). Implantation into rodents of impervious solid foreign bodies made from a wide variety of materials also induces sarcomas in the surrounding tissues. Materials include polystyrene, cellophane, polyethylene, polyurethane, polyvinylchloride, polymethylmethacrylate, silicone, glass, aluminium oxide and metals such as stainless steel, gold, platinum, titanium, nickel, chromium (Oppenheimer et al. 1964; Brand et al. 1976; Kirkpatrick et al. 2000). Implantation of spent uranium fragments also induces sarcomas (Hahn et al. 2002). There are species and strain differences in the sensitivity of rodents to the induction of sarcomas by foreign bodies, the heterozygous transgenic $\mathrm{p} 53^{+/-}$being particularly sensitive (Blanchard et al. 1999). Again the main induced type of neoplasm is fibrosarcoma or its pleomorphic variant although other types are also reported. Sarcomas developing around implants appear to be very rare in humans (Morgan and Elcock 1995; Keegan et al. 2008).

Most of these rodent neoplasms can be diagnosed by the use of routine hematoxylin and eosin stained sections, although immunocytochemistry can be used to characterize cell types more accurately. In the diagnosis of human soft tissue sarcomas, immunocytochemistry now has an important place. It has been shown that this can assist in the sub-categorization of pleomorphic sarcomas and the assessment of prognosis and proper planning of therapy (Coindre et al. 2001; Tos 2006). However, in rodents the diversity of tumor types is far more limited. A recent study of a large number of fibrosarcomas and liposarcomas induced in different studies by peroxisome proliferator-activated receptor agonists in rats immunohistochemistry was relatively unhelpful in the characterization and grouping of these tumors for the purpose of safety assessment (Hardisty et al. 2007).

- Fibroma

- Fibrosarcoma

- Fibrosarcoma, pleomorphic

- Lipoma

- Hibernoma

- Liposarcoma

- Rhabdomyoma: There is no fully substantiated report of rhabdomyoma occurring in laboratory rats or mice.

- Rhabdomyosarcoma

- Leiomyoma

- Leiomyosarcoma

- Mesenchymoma, malignant

- Sarcoma, NOS (Not otherwise specified)

- Mesothelioma, malignant

\section{Infiltrate, inflammatory cell (N): Soft Tissue}

Species: Mouse, Rat

Synonym: Aggregate

Modifiers: Mononuclear cell, Lymphocyte, Neutrophil, Eosinophil, Plasma cell, Polymorphonuclear cell, Mixed cell. Pathogenesis: May be a normal physiological appearance.

Diagnostic features

- Small foci of mononuclear cells, lymphocytes, plasma cells or polymorphonuclear cells.

- No evidence of tissue damage.

Comment: These descriptive terms are applied to localized accumulations of lymphocytic, mononuclear or polymorphonuclear (neutrophils or eosinophils) cells that do not constitute evidence of a significant inflammatory process. They may be considered within physiological limits. 
Inflammation (N) (Figures 1-3): Soft Tissue

Species: Mouse, Rat

Synonyms: Abscess, Granulation tissue, Granuloma

Modifiers: Neutrophil (purulent), Lymphocyte (nonpurulent), Eosinophil, Plasma cell, Mononuclear cell, Mixed cell, Granulomatous.

Pathogenesis: Non-specific response to injury.

Diagnostic features

- Infiltration of leukocytes into the extracellular matrix.

- Often accompanied by edema and intravascular accumulation of leukocytes.

- Can be associated with prominent in-growth of fibroblasts and blood vessels (granulation tissue) typically in 2-3 days after injury.

Granuloma

- Represents a focal form of inflammation characterized by aggregates of histiocytes often with epithelioid appearance seen in isolation.

- May have a central zone of necrosis.

- Sparse infiltrate of other cells such mononuclear cells, polymorphonuclear leukocytes, blood vessels and fibroblasts.

Abscess

- Neutrophils accumulate focally and show central cell lysis with accumulation of cellular debris.

- Fibrous capsule formation

- Modifiers can be used to describe the most prominent character of the inflammatory process:

Neutrophil (purulent)

- Infiltration of neutrophils predominates.

Lymphocyte (non-purulent)

- Infiltration of lymphocytes and macrophages (mononuclear leukocytes) predominates.

- Plasma cells may be prominent.

Eosinophil

- Infiltration of eosinophilic granulocytes predominates.

Granulomatous

- An inflammatory process involving a significant proportion of macrophages and other mononuclear cells.

- Macrophages might adopt an epithelioid phenotype or form foreign body type giant cells (syncytia).

- There may be a central zone of necrosis.

- It may be surrounded by granulation tissue, blood vessels and fibroblasts.

- May be surrounded by a fibrous capsule

Differential diagnoses

Fibrosis and fibroplasia

- A very limited number of leukocytes, predominately mononuclear cells, extracellular collagen matrix not associated with active inflammation or a predominantly fibroblastic response.

Fibroma:

- Dense, poorly cellular fibrous mass of well-differentiated fibroblasts, compressing adjacent tissue; interwoven bands of mature collagen; rare mitotic figures; very little if any leukocyte infiltration.

Sarcoma, histiocytic:

- Comprised of fairly uniform but large histiocytic cells with vesicular nuclei and may show mitotic activity.

Comment: It should be underlined that the term 'inflammation' should be limited to those instances where there is evidence of a pathological inflammatory process. Descriptive terms such as lymphocyte or neutrophil aggregates or infiltration should be applied to localized accumulations of lymphocytic, monocytic or polymorphonuclear cells that may be considered within physiological limits (see Infiltrate, inflammatory cell).

Localized inflammatory processes in connective tissue usually develop as a consequence of local trauma, ulceration of the overlying epithelium, infarction, injection or implantation of foreign materials into soft tissues or their extravasation from blood vessels. Systemic effects of xenobiotics may also occasionally result in damage to the soft tissue without a local inciting cause being evident in the sections. Histological features may be modified by the nature and duration of the damage and type of tissue involved.

Initially, tissue damage or necrosis is accompanied by variable amounts of hemorrhage and edema and acute inflammatory cells, followed by mononuclear leukocytes. Within two or three days there is proliferation of fibroblasts and angiogenesis which is the basis for 'granulation tissue'. Subsequently, fibroblasts synthesize significant amounts of collagen usually reaching a peak by about the third week (fibroplasia). Remodeling of collagen ultimately occurs to produce mature scar tissue possessing high tensile strength (fibrosis).

If the inflammatory process is prolonged, chronic inflammation characterized predominantly by the presence of lymphocytes, plasma cells and macrophages develops. A fibroblastic response may also be prominent. Activated fibroblasts acquire -smooth muscle cell-like phenotype, often referred to as myofibroblasts. These not only synthesize and deposit extracellular matrix but also have contractile properties mediated by -smooth muscle actin organized in bundles of microfilament (Hinz 2010).

A foreign body reaction with giant cells, abscess or cyst formation may also develop. Mineral can also be deposited at the site of injured tissue (dystrophic mineralization). This is characterized by fine or coarse granular deposits staining intensely with hematoxylin or positively with the von Kossa stain. Iron pigments 
(hemosiderin) may also be found particularly in macrophages when hemorrhage has occurred.

A granuloma represents a localized form of an inflammatory reaction in which the cells are similar to those in the reparative phase of the inflammatory process but in which the histiocytic component is predominant. The term granulomatous inflammation is used when there is a predominance of histiocytes and macrophages often showing epithelioid features or foreign body giant cell formation. They form as a local reaction to foreign materials but also more widely in soft tissue in response to infectious agents or as an immunological granulomatous inflammatory reaction. They may also develop as an expression of altered function of cells of the monocyte/macrophage series (Westwood et al. 1995).

Whilst the basic inflammatory response is common to all forms of tissue injury, different injected or implanted materiel may modify certain histological features. For instance, smooth surfaced biomaterials may produce smaller fibrous capsules that textured implants (Williams 1987; Picha et al. 1990). Pure aluminium metal implants are reported to induce a narrow zone of necrosis, copper a more vascular response and cobalt is associated with significant lymphoid infiltrates (McNamara and Williams 1981).

Fibrosis (N): Soft Tissue

Species: Mouse, Rat

Synonyms: Scar formation, Sclerosis

Pathogenesis: Repair process after local tissue degeneration.

Diagnostic features

- Focal to focally extensive increase in extracellular collagen.

- Low number of fibroblasts.

- Collagen fibers are mostly arranged in long streams.

- Collagen fibers replace specialized normal cutaneous adnexae.

\section{Differential diagnoses}

Fibroma

- Dense, poorly cellular fibrous mass of well-differentiated fibroblasts, compressing adjacent tissue; interwoven bands of mature collagen; rare mitotic figures; very little if any leukocyte infiltration.

Fibrosarcoma

- Very cellular, composed of abnormal pleomorphic fibroblastic cells showing high mitotic activity.

Inflammation

- Infiltration of leukocytes predominates.

fibroplasia

- Cellular, containing numerous active fibroblasts which although may be plump, show no atypical fea- tures.

Comment: Fibrosis is usually but not always the end stage of a chronic inflammatory process. In contrast to active inflammatory processes or neoplasia it is usually poorly cellular.

\section{Fibroplasia (N): Soft Tissue}

Species: Mouse, Rat

Pathogenesis: Active repair process after local tissue damage.

Diagnostic features

- Variable increase in extracellular stroma.

- High number of proliferating, active plump but normal fibroblasts.

Differential diagnoses

Fibrosis:

- Poorly cellular fibrous tissue containing few fibroblasts; very little if any leukocyte infiltration.

Fibroma:

- Dense, poorly cellular irregular fibrous mass of welldifferentiated fibroblasts, compressing adjacent tissue; interwoven bands of mature collagen; rare mitotic figures; very little if any leukocyte infiltration.

Fibrosarcoma

- Very cellular, composed of abnormal pleomorphic fibroblastic cells showing high mitotic activity. Inflammation:

- Infiltration of leukocytes predominates.

Comment: The term fibroplasia is used to denote the presence of abundant active, fibroblasts. A fibroblastic response without significant inflammation has been reported in the adipose tissues of rodents treated with peroxisome proliferator-activated receptor agonists (Hardisty et al. 2007; Waites et al. 2007).

The differential diagnosis between an exaggerated fibroblastic response to tissue injury and a mesenchymal tumor (fibroma or fibrosarcoma) is usually made on the basis of size and growth pattern. Neoplasms are usually large and show evidence of nodularity with compression and infiltration of local tissues and adjacent organs. Careful studies of the biomaterial-induced sarcomas have shown a spectrum of change from nonneoplastic fibroblastic proliferation to incipient sarcoma. These premalignant zones are characterised by cellular and nuclear pleomorphism, hyperchromasia and prominent nucleoli that can be more easily identified by use of immunocytochemistry for proliferating cell nuclear antigen (Kirkpatrick et al. 2000).

Necrosis (N): Soft Tissue

Species: Mouse, Rat Pathogenesis: Cell death.

Diagnostic features 
- Loss of cellular detail and loss of nuclei (coagulation necrosis).

- Replacement by cellular debris (lytic necrosis).

- Often associated with edema, hemorrhage, vascular congestion, infiltration of leukocytes, accumulation of fibrin, formation of granulation tissue, cyst formation, mineralization and deposition of iron pigment (hemosiderin).

Differential diagnoses

Inflammation:

- Infiltration of leukocytes predominates.

\section{Mineralization (N): Soft Tissue}

Species: Mouse, Rat

Synonym: Calcification

Pathogenesis: Local injury (dystrophic mineralization), or generalized mineral imbalance (metastatic mineralization).

Diagnostic features

- Intracellular and/or extracellular deposition of fine or coarse irregularly shaped granules staining intensely basophilic with hematoxylin.

- May be associated with infiltration by macrophages (including giant cells), lymphocytes and fibroblasts.

- Stains with histochemical reactions for minerals (e.g. calcium).

- Is mostly associated with other signs of injury (e.g. necrosis).

Differential diagnoses

Osseous Metaplasia:

- Bone tissue may be diagnosed histologically.

Comment: Mineral deposits can occur in the soft tissues (particularly the subcutis) of rodents, either following local tissue injury (dystrophic mineralization) or under circumstances that favour generalized mineralization. These include high dietary calcium:phosphate ratio, treatments that mobilize body calcium stores or raise blood calcium levels (metastatic mineralization) and chronic renal failure. When calcium balance is disturbed, soft tissues most commonly affected in the rodents appear to be natural localised trauma sites such as around the limbs and in breeding females' mammary tissues.

\section{Metaplasia (N): Soft Tissue}

Species: Mouse, Rat

Modifiers: Osseous, Cartilaginous type

Diagnostic features

- Cartilage or bone structure, abnormally located within collagenous connective tissue.

- Often surrounded by granulation tissue.

Osseous

- Osteoid, calcified bone tissue and even bone marrow.
Cartilaginous type

- Cartilage

Differential diagnoses

Mineralization

- Intracellular or extracellular deposits of mineral, no cartilage or bone formation.

Comment: Osseous metaplasia is a well-recognized phenomenon occurring in tissues affected by a variety of pathologic processes notably ischemia, hematoma and chronic inflammation, various degenerative and reparative changes as well as within neoplasms (Liu et al. 2007).

Amyloid (N): Soft Tissue

Species: Mouse, Rat

Pathogenesis: Accumulation of an insoluble protein with $\beta$-pleated sheet secondary structure.

Diagnostic features

- Extracellular deposition of pale, amorphous, eosinophilic, hyaline material.

- Compression of adjacent tissue may be present.

- Can be associated with edema.

Special techniques for diagnosis

- Shows reddish metachromasia with crystal violet. Congo red stains amyloid orange-red and shows apple-green dichroism in polarizing light.

Differential diagnoses

Necrosis with deposition of fibrin

- Congo red staining is negative.

Deposition of other proteinacous material: Hyaline, Mature collagen

- Congo red staining is negative.

Comment: In mice, amyloid deposits only occur when there is significant systemic amyloid (Faccini et al. 1990). In general, amyloidosis appears to be more common in aging CD-1 mice, compared with other conventional strains (Majeed 1993).

\section{Infiltrate, inflammatory cell (N): Adipose Tissue}

Species: Mouse, Rat

Synonym: Aggregate

Modifiers: Mononuclear cell, Lymphocyte, Neutrophil, Eosinophil, Plasma cell, Polymorphonuclea cell, Mixed cell.

Pathogenesis: May be a normal physiological appearance.

Diagnostic features

- Small foci of mononuclear cells, lymphocytes, plasma cells or neutrophils.

- No evidence of tissue damage.

Comment: These descriptive terms are applied to local- 
ized accumulations of lymphocytic, mononcytic or polymorphonuclear cells that do not constitute evidence of a significant inflammatory process. They may be considered within physiological limits.

\section{Inflammation (N): Adipose Tissue}

Species: Mouse, Rat

Synonyms: Abscess, Granulation tissue, Granuloma.

Modifiers: Neutrophil (purulent), Lymphocyte (nonpurulent), Eosinophil, Plasma cell, Mononuclear cell, Mixed cell, Granulomatous.

Pathogenesis: Non-specific response to injury.

Diagnostic features

- Infiltration of leukocytes among fat cells and extracellular matrix.

- Often accompanied by edema and intravascular accumulation of leukocytes.

- Can be associated with prominent in-growth of fibroblasts and blood vessels (granulation tissue) in 2-3 days after injury.

Comment: As in other tissue adipose tissue may be affected by a typical inflammatory process which shows similar histological features (see soft tissue Inflammation).

Inflammation, lipogranulomatous (N) (Figure 3): Adipose Tissue

Species: Mouse, Rat

Synonyms: Steatitis, Obesity-associated inflammation

Pathogenesis: Response of adipose tissue to injury.

Diagnostic features

- Gross pathology: widespread small white or yellowish foci in adipose tissue.

- Clusters of macrophages often with small lipid vacuoles in the cytoplasm (foam cells).

- Cholesterol clefts, surrounded by giant cells may occur.

- Proliferation of blood vessels and connective tissue may occur.

Special techniques for diagnosis

- Presence of lipofuscin droplets (demonstrated by their autofluorescence): Lipofuscin is acid fast and shows yellow autofluorescence in fluorescent light.

Differential diagnoses

Liposarcoma:

- Shows histological features of malignancy such as pleomorphic spindle cells, mitotic activity, necrosis and the presence of lipoblasts.

Comment: Inflammatory processes may affect adipose tissue in a similar manner to the other soft tissues (see Inflammation). In addition, some more specific forms of inflammation may be seen. Obesity in rodents as well as humans has been associated with a widespread focal form of inflammation in the adipose tissue, characterized by the presence of macrophages (Weisberg et al. 2003; Wellen and Hotamisligil 2003; Xu et al. 2003). Another form of generalized fat damage affecting adipose tissue in the rat termed 'steatitis' is believed to be the result of accumulation of pigment as a result of phagocytosis of blood-borne or interstitial reactive lipid molecules. It appears to develop as a result of vitamin E or antioxidant deficiency. This may develop as a consequence of excess dietary polyunsaturated fatty acids with a least three double bonds such as found in fish or linseed oil (Danse 1989).

Focal damage to fat cells occurs under a variety of circumstances. Histologically, evidence of necrosis may be lacking but there is often a sparse accumulation of inflammatory cells including macrophages and giant cells. Clefts representing dissolved rhomboidal cholesterol crystals may also be seen.

\section{Necrosis (N) (Figure 4): Adipose Tissue}

Species: Mouse, Rat

Synonym: Fat necrosis

Pathogenesis: Cell death.

Diagnostic features

- Loss of cellular detail and ghost-like appearance of fat cells.

- May be associated with edema, hemorrhage, vascular congestion, infiltration of leukocytes, accumulation of fibrin, formation of granulation tissue, cyst formation, fibrosis and deposition of iron pigment (hemosiderin) or calcium.

Differential diagnoses

Inflammation

- Infiltration of leukocytes predominates.

Atrophy (N): Adipose Tissue

Species: Mouse, Rat

Synonyms: Lipoatrophy, Fat atrophy

Modifiers: Serous, Mucoid

Diagnostic features

- Loss or reduction in size of fat cells.

- May be increase in connective tissue or fibrous septa.

- May show extracellular glycosaminoglycan (mucopolysaccharides)

Differential diagnoses

Lipoma

- Reduction in size of lipocytes is localised within the neoplasm and there is expansion and compression of surrounding tissues.

Comment: Loss of adipose tissue normally occurs under conditions where there is reduced caloric intake or 
increased energy expenditure. Other forms of atrophy may also occur. Loss of fat (lipoatrophy) in face, limbs, and abdominal subcutaneous region has been reported in people infected with the human immunodeficiency virus who are receiving highly active antiretroviral therapy (Flint et al. 2009; Sevastianova et al. 2011). Analogous findings are reported in rodents (Prot et al. 2006). Localized fat atrophy may also be related to injected drugs such as insulin and corticosteroids as well as recurrent pressure and inflammation of adipose tissue (Garg 2004; Larade et al. 2008). In cachectic states pale staining amorphous extracellular glycosaminoglycan may become visible in atrophic adipose tissue and this can be termed serous atrophy (Munfus and Menke 2009).

\section{Hyperplasia, adipose tissue (H): Adipose Tissue}

Species: Mouse, Rat

Synonym: Polymorphic adipose tissue

Diagnostic features

- Diffuse (or focal) increase of adipose tissue with macrovesiculation (white adipose tissue) or microvesiculation (brown adipose tissue).

- Can be associated with variable focal fibrosis or fibroblastic proliferation (fibroplasia).

- No compression of surrounding tissue.

Differential diagnoses

Lipoma

- Discrete rounded nodules of adipose tissue showing compression of the surrounding stroma.

Liposarcoma

- Shows histological features of malignancy such as pleomorphic spindle cells, mitotic activity, necrosis and the presence of lipoblasts.

Comment: Hyperplasia of adipose tissue has been described in rodents following administration of peroxisome proliferator-activated receptor agonists and has been attributed to a receptor-mediated pharmacodynamic process (Hardisty et al. 2007; Waites et al. 2007).

Hyperplasia, smooth muscle (H): Soft Tissue

Species: Mouse, Rat

Diagnostic features

- Poorly circumscribed areas or bundles of irregular or parallel smooth muscle fibers.

- Well-differentiated smooth muscle cells with eosinophilic cytoplasm, distinct cell boundaries and cylindrical, blunt-ended or cigar-shaped nuclei.

- Longitudinal myofibrils can be demonstrated in the cytoplasm using the phosphotungstic acid-hematoxylin (PTAH) stain.

Differential diagnoses
Leiomyoma

- Is composed of interlacing bundles and whorls of smooth muscle cells showing a nodular growth pattern and compression of surrounding tissues.

Comment: Hyperplasia of smooth muscle is typically reported in the walls of the uterus, mesovarium, gastrointestinal tract or blood vessels in rodents rather than in soft tissues per se (Gopinath and Gibson 1987; Parrott et al. 2001).

\section{Infiltrate, inflammatory cell (N): Skeletal Muscle}

Species: Mouse, Rat

Synonym: Aggregate

Modifiers: Mononuclear cell, Lymphocyte, Neutrophil, Eosinophil, Plasma cell, Polymorphonuclear cell, Mixed cell

Pathogenesis: May be a normal physiological appearance.

Diagnostic features

- Small foci of mononuclear cells, lymphocytes, plasma cells or neutrophils.

- No evidence of tissue damage.

Comment: These descriptive terms are applied to localized accumulations of mononuclear cells, polymorphonuclear cells, lymphocytes, plasma cells or mixed infiltrates that do not constitute evidence of a significant inflammatory process. They may be considered within physiological limits.

\section{Necrosis (N) (Figures 5 and 9): Skeletal Muscle}

Species: Mouse, Rat

Pathogenesis: Response to injury.

Diagnostic features

- Necrosis, edema and hemorrhage.

- Rounded, hyalinized fibers with pyknotic nuclei (first few hours),

- Loss of cross striations.

- Fragmentation of muscle fibers (24 hours).

- Polymorphonuclear leukocyte infiltrate (peak at 1 to 2 days).

- Infiltration of macrophages and proliferation of myoblasts, may form myotubules with long chains of nuclei (day 3).

- Regeneration of basophilic muscle fibers (day 5).

- Repair complete (3 weeks).

Differential diagnoses

Myopathy (see Degeneration, Vacuolation)

- Vacuolation of fibers or basophilic droplets or targetoid fibers with no or very little inflammation.

Comment: The characteristic process of muscle degeneration which leads to necrosis, inflammation and repair is observed following the intramuscular injection of myotoxic agents. Small amounts of localised fiber 
necrosis may even occur following injection of innocuous substances including saline (Thuilliez et al. 2009).

In the first few hours following injection fibers become rounded and hyalinized with pyknotic nuclei. Myofibers often exhibit focal or segmental necrosis because of their length and multiple nuclei. Necrotic fibers are surrounded by variable degrees of hemorrhage and edema. Within 24 hours affected fibers become overtly fragmented and macrophages can be seen. By day three, lesions are composed of numerous infiltrating macrophages accompanied by proliferating myoblasts which may form myotubules with long chains of nuclei. After five days there are numerous regenerating muscle fibers characterized by basophilic cytoplasm and vesicular nuclei and prominent nucleoli.

Satellite cells around intact muscle fibers in the region of necrotic muscle may also show activation. Affected satellite cells show increased cytoplasmic volume and mitotic activity and are separated from skeletal muscle fibers by an unusually wide space which may contain prominent basal lamina.

Finally, regenerating fibers subsequently enlarge and by three weeks after injury, the muscle tissue becomes essentially normal although fibers may retain some central nuclei (Manor and Sadeh 1989). Although regeneration following local damage is surprisingly complete, muscle fibers may not regenerate after severe, extensive or repeated damage and as a consequence fibrous scarring may follow.

Skeletal muscle degeneration and necrosis can occur after systemic exposure to a variety of xenobiotic and different fiber types may be affected (Greaves 2012). Type II or fast twitch fibers appear to be the most sensitive to inhibitors of hydroxymethylglutaryl-coenzyme A (HMG-CoA) reductase (statins) (Westwood et al. 2005) whereas type I fibers appear to be generally more sensitive to the adverse effects of peroxisome proliferator-activated receptor (PPAR) agonists (De Souza et al. 2006; Faiola et al. 2008).

\section{Inflammation (N) (Figure 5): Skeletal Muscle}

\section{Species: Mouse, Rat}

Synonyms: Abscess, Granulation tissue, Granuloma Modifiers: Neutrophil (purulent), Lymphocyte (nonpurulent), Eosinophil, Plasma cell, Mononuclear cell, Mixed cell, Granulomatous.

Pathogenesis: Non-specific response to injury.

Diagnostic features

- Infiltration of leukocytes among muscle fibers and extracellular matrix.

- Often accompanied by edema and intravascular accumulation of leukocytes.

- Can be associated with prominent in-growth of fibroblasts and blood vessels (granulation tissue) in 2-3 days after injury.
Comment: As in other tissue skeletal muscle may be affected by a primary inflammatory process associated with little or no overt necrosis.

\section{Hypertrophy (N): Skeletal Muscle}

Species: Mouse, Rat

Diagnostic features

- Enlargement of muscle fibers.

Comment: Hypertrophy of muscle fibers may be focal or diffuse. Focal compensatory hypertrophy may occur in muscle showing atrophic alterations. Diffuse hypertrophy can develop in response to increased exercise or as a response to prolonged excessive growth factors such as growth hormone or growth-promoting xenobiotics (Prysor-Jones and Jenkins 1980; McClung et al. 2005). Growth hormone has been shown to affect mainly type I fibers. Hypertrophy is characterized histologically by an increase in muscle fiber diameter but this may be difficult to assess histologically without morphometric analysis.

\section{Atrophy (N): Skeletal Muscle}

Species: Mouse, Rat

Synonyms: Denervation atrophy, disuse atrophy, nutritional atrophy, age-related atrophy.

Diagnostic features

- Decreased muscle fiber size, presence of angulated fibers.

- Replacement by adipose tissue.

Differential diagnoses

Myopathy (see Degeneration, Vacuolation):

- Vacuolation, targetoid fibers or hyaline change.

Comment: Atrophy of skeletal muscle may result from inactivity or cachexia as well as primary degenerative processes originating in muscle fibers. It also occurs secondary to denervation (denervation atrophy). These types of atrophy can be induced experimentally in rodents. Moreover, atrophy of skeletal muscle occurs spontaneously in rats in advancing age although whether the changes result from primary muscle degeneration or changes in the nerve supply is disputed.

The nature of an individual muscle fiber is determined by its innervation and as a consequence all fibers supplied by an individual neuron are of the same type. The distribution of fiber type varies between muscles. For instance the soleus muscle in the F344 rat comprises over $80 \%$ of type I fibers whereas the extensor digitorum longus contains mainly type II fibers (Eddinger et al. 1985). Normally, different fibers are intermingled randomly within a muscle. Consequently if a neurone supplying a muscle motor unit dies, the muscle fibers supplied by that unit undergo atrophy and take on a characteristic histological feature of denerva- 
tion atrophy that of a compressed angular profile when seen in cross section.

Ultimately, surviving intramuscular axons form collateral branches which connect with denervated fibers which then display histochemical characteristics of the type determined by the new innervations (Behan et al. 2002). A characteristic grouping of the fibers into homogeneous groups of fiber type rather than the mosaic pattern of normal muscle develops following re-innervation (Brooke et al. 1971). Furthermore, if a neuron supplying the enlarged motor unit degenerates, atrophic fibers are more likely to be grouped together and surviving fibers may undergo compensatory hypertrophy to give a characteristic histological pattern of both atrophy and hypertrophy.

Atrophy from non-neurogenic causes such as those induced by the administration of myotoxic xenobiotics is usually characterized by the lack of angulated fibers and the presence of myopathic changes such as necrotic or rounded hyaline fibers, centrally nucleated cells and divided or so called 'split fibers' (see Degeneration). The muscle atrophy and increased protein catabolism that follows chronic administration of corticosteroids in the rat is characterized by uncomplicated reduction in the size of type II fast twitch fibers (Livingstone et al. 1981). This is most readily observed in type II fiberrich muscles such as the biceps femoris.

In aging rats, atrophy of muscle fiber affects predominantly the hind limbs. There is atrophy of muscle fibers, increased variation in muscle fiber size and accumulation of degenerative inclusion bodies, lipofuscin and lipid droplets and increased connective tissue (Everitt et al. 1985). The presence of angular fibers suggests that the changes may result from spinal degeneration.

\section{Degeneration (N) (Figures 6-9): Skeletal Muscle}

Species: Mouse, Rat

Synonyms: Myopathy, Myopathic changes, Cytopathic changes

Diagnostic features

- Vacuolation of fibers.

- Basophilic cytoplasmic droplets (phospholipid).

- Targetoid fibers.

- Split fibers.

- Hyaline changes.

Differential diagnoses

A variety of different pathological processes are embraced under this term. Clear distinction often requires special staining techniques to clarify the precise nature of the degenerative alterations. In view of the overlap between degeneration and other cytological changes that can be seen in skeletal muscle some prefer the more general term myopathy to embrace all such alterations including simple vacuolation (see Vacuolation).
Comment: Pathologic insults to muscle may lead to a variety of cytopathic changes in muscle fibers. The precise nature of the changes is dependent on the nature of the damage. Following systemic administration of agents which have a direct myotoxic effect such as 6-mercaptopurine, vincristine and emetine, muscle fibers exhibit rounding, vacuolation, hyalinization with loss of myofibrils, pale staining central zones (targetoids) and split fibers (Jaweed et al. 1985).

\section{Vacuolation (N): Skeletal Muscle}

\section{Species: Mouse, Rat}

Synonyms: Myopathy, Myopathic changes, Cytopathic changes

\section{Diagnostic features}

- Fibers contain clear, pale or basophilic cytoplasmic vacuoles.

Comment: Round cytoplasmic basophilic bodies of up to $3 \mu \mathrm{m}$ in diameter composed ultrastructurally of laminated membranous material (spheromembranous bodies) have been described in the muscles of rats treated with agents such as vincristine, colchicine and chloroquine (Slotwiner et al. 1966; Clarke et al. 1972; Seiden 1973; Bradley et al. 1976).

Some agents inducing systemic phospholipidosis produce vacuolation of skeletal muscle cells. Muscle vacuoles usually appear empty in routinely processed sections stained with hematoxylin and eosin but in toluidine blue stained plastic embedded sections they stain dark blue. Ultrastructural examination shows that they are composed of lamellated membranous inclusions associated with lysosomes. Glycogen, neutral lipid may also be present in vacuoles in skeletal muscle. Swollen or giant mitochondria may also appear as pale vacuoles in conventional histological sections.

\section{Mineralization (N): Skeletal Muscle}

Species: Mouse, Rat

Comment: Mineralization of dystrophic or metastatic type may be observed within skeletal muscle. It shows histological characteristic which are similar to mineral in other tissue (see Mineralization).

\section{Hyperplasia (H): Mesothelium}

Species: Mouse, Rat

Diagnostic features

- Usually localized but may be diffuse.

- Focal thickening or villous projections covered by relatively uniform cuboidal cells with little or no stratification, usually limited to $1-2$ cells in thickness.

- Lacks evidence of significant mitotic activity.

- Little or no cellular atypia.

- May possess a small fibrovascular core or stalk.

- Fibrosis or inflammation may accompany the chang- 
es.

\section{Differential diagnoses}

Mesothelioma, malignant

- Is highly cellular and pleomorphic and shows extensive spread within the body cavities or infiltrates adjacent tissues.

Epithelioid Mesothelioma, malignant

- Exhibits poorly formed glandular structures or illformed glands.

Sarcomatoid mesothelioma, malignant

- Consists of spindle-shaped cells with elongated nuclei.

Comment: These are often small incidental lesions seen in the pleura, pericardium, peritoneum or tunica vaginalis (McConnell et al. 1992).

In inhalation studies fiber-associated lesions most frequently are found at the parietal pleura.

Fibroma (B) (Figures 10 and 11): Soft Tissue

Species: Mouse, Rat

Synonym: Benign fibrous histiocytoma

Diagnostic features

- Dense, poorly cellular fibrous mass, compressing adjacent tissue.

- Interwoven bands of mature collagen.

- Interlacing bundles of well-differentiated fibroblasts.

- Fusiform cells with elongated, tapered, hyperchromatic or vesicular nuclei with one or more nucleoli.

- Rare mitotic figures.

- May have pale blue staining myxomatous areas and stellate cells.

- May show well-differentiated fibroblasts and collagen bundles showing infiltration of the musculature but without cytological features of malignancy.

Differential diagnoses

Fibrosis and fibroplasia

- No neoplastic features, associated with wounds, ulcers or inflammation.

Fibroadenoma of mammary glands

- Glandular elements within fibrous tumor tissue.

Fibrosarcoma

- Shows marked cellularity, cellular pleomorphism, increased mitotic activity, necrosis, tissue invasion and metastases.

Comment: Tumor cells can be arranged in a storiform or cartwheel pattern producing short thin bundles of collagen. This pattern was formerly classified as 'benign fibrous histiocytoma'. This term is now not usually used.

Fibromas are occasionally seen in untreated rats but they are rarer in untreated aged mice (Boorman et al. 1989; Heider and Eustis 1994). In rats, a fibroma of desmoid type (also known as fibromatosis-type) has been described as postoperative lesion in Bhd gene mutant rats (Kouchi et al. 2008). This form of fibroma may occasionally be seen in conventional strains. Fibromas have also been reported to develop in Wistar rats at the site of repeated injection of low doses of iron dextran solution (Roe and Carter 1967). Myxomatous areas sometimes contain star-shaped fibroblasts (stellate cells).

\section{Fibrosarcoma (M) (Figure 12): Soft Tissue}

Species: Mouse, Rat

Diagnostic features

- Solid fibrous mass.

- Monomorphic interwoven fascicles of spindle cells with oval nuclei and basophilic cytoplasm.

- Cells often arranged in a 'herring-bone' pattern.

- Variable collagen content depending on the degree of differentiation.

- Extensive local invasion.

- Areas of hemorrhage and necrosis.

- May have metaplastic bone and cartilage (non-neoplastic).

- May have plentiful mitotic figures.

- Can predominantly consist of pale blue staining myxomatous areas with stellate cells.

Differential diagnoses

Fibroma and fibroplasia

- No cellular atypia, low mitotic rate.

Fibrosarcoma, pleomorphic

- Storiform pattern of uniform plump spindle cells to a highly pleomorphic pattern of bizarre spindle cells and tumour giant cells.

Liposarcoma (myxoid type)

- Fat forming cells within myxomatous tissue.

Comment: There is no sharp division between monomorphic fibrosarcoma and more pleomorphic variants. Along with the pleomorphic sarcoma these are the most common sarcoma type induced by injection of chemicals or implantation of solid materials (see pleomorphic fibrosarcoma below). Myxomatous areas sometimes contain star-shaped fibroblasts (stellate cells).The presence of neoplastic bone, cartilage, muscle or other differentiated features are diagnostic of other sarcoma types or mesenchymoma where there are two or more types of differentiation (see Sarcoma, NOS (Not otherwise specified), Fibrosarcoma, pleomorphic, Liposarcoma, Rhabdomyosarcoma, Leiomyosarcoma).

Fibrosarcoma, pleomorphic (M) (Figure 13): Soft Tissue

Species: Mouse, Rat 
Synonym: Malignant fibrous histiocytoma.

Diagnostic features

- Solid fibrous mass.

- Variable histology ranging from storiform pattern of uniform plump spindle cells, small rounded cells, to a highly pleomorphic pattern of bizarre spindle cells and tumor giant cells.

- Abundant but variable amount of interstitial collagen.

- Ground substance variable but may show myxomatous zones.

- Widespread infiltration and invasion of local tissues.

- Areas with hemorrhage and necrosis.

- Variable mitotic activity.

Differential diagnoses

Fibroma and fibroplasia

- No cellular atypia, low mitotic rate.

Fibrosarcoma

- Monomorphic spindle cells

- Lacks storiform pattern and shows no cellular pleomorphism or tumor giant cells.

Sarcoma, histiocytic

- Contains rounded histiocyte-like cells, Langhans type giant cells and shows immunoreactivity or CD68 (rats) or F4/80 (mice).

Rhabdomyosarcoma

- Cells contain PTAH-positive cross-striations and immune-reactivity for myoglobin.

Sarcoma, NOS (Not otherwise specified)

- No histological characteristics that enable categorization.

Comment: In both laboratory animals and humans tumors of this type have been frequently termed malignant fibrous histiocytomas. They are considered to be a group of largely undifferentiated or primitive sarcomas. In humans they are now often subdivided according to their immunohistochemical and electron microscopic characteristics (Fletcher 1987; Fletcher 2006). Similar sarcomas have been well characterized in rodents where they develop spontaneously. They are the most common type induced in rats by carcinogens and noncarcinogenic chemicals, subcutaneous implants and viruses (Chesterman et al. 1966; Konishi et al. 1982; Wright et al. 1991; Tsuchiya et al. 1993; Schneider et al. 1999; Kirkpatrick et al. 2000). Identical neoplasms occur in the mouse under similar circumstances where they have been variously known as malignant fibrohistiocytomas or pleomorphic fibrosarcomas (Brand et al. 1976; Stewart 1979; Faccini et al. 1990). A mononuclear or polymorphonuclear infiltrate is sometimes seen and blood vessels can be prominent. Collagen formation usually is marked in spindle cell zones and myxoid change can develop. Large lesions may show necrosis and ulceration of overlying skin. Metastases may occasionally occur in lung, liver and other organs. Those that develop in the peritoneal cavity may spread along the visceral and parietal peritoneum and mesentery surrounding abdominal organs (Shoieb et al. 2012).

These sarcomas are the most common type induced in rodents by powerful carcinogenic chemicals such as polycyclic hydrocarbons as well as the repeated subcutaneous injection of agents not considered carcinogens. Substances among the latter class include concentrated solutions of glucose and other sugars, sodium chloride, certain water-soluble food colourings and surfactants, carboxymethycellulose and macromolecular dextrans (Grasso and Goldberg 1966a; Grasso and Goldberg 1966b; Carter 1970; Carter et al. 1971; Hooson et al. 1973).

Some of these materials such as macromolecular iron dextrans have been used therapeutically in humans by the parenteral route for many years without evidence of tumour induction (Carter 1970).

Subcutaneous implantation of inert plastics, metals and other materials of certain dimensions can likewise give rise to sarcomas around implantation sites in rodents, the so called 'Oppenheimer effect' or 'solid state' carcinogenesis (Oppenheimer et al. 1953; Autian 1973; Brand et al. 1976; Kirkpatrick et al. 2000; Hahn et al. 2002). These sarcomas also develop around small glass and polypropylene covered microchips implanted into the subcutaneous tissues of heterozygous transgenic p53+/- mice within periods as little as 15 weeks (Blanchard et al. 1999). However, sarcomas have been induced by implanted microchips in Fischer 344 rats and various conventional mouse strains. Reported incidences in implanted Fischer rats is about $1 \%$ and mice they range between about 2 and $4 \%$ in $\mathrm{B} 6 \mathrm{C} 3 \mathrm{~F} 1$ mice, $1.2 \%$ in $\mathrm{CBA} / \mathrm{J}$ female mice, $0.5 \%$ in $\mathrm{CBA} / \mathrm{J}$ male mice whereas CD-1 mice are more resistant(Tillmann et al. 1997; Elcock et al. 2001; Le Calvez et al. 2006).

Lipoma (B) (Figures 14 and 15): Soft Tissue

Species: Mouse, Rat

Modifier: Angiomatous Type

Diagnostic features

- Soft nodular, well-demarcated, lobulated fatty mass displacing surrounding tissue.

- Mature fat cells each typically containing a single fat vacuole with eccentrically located nucleus.

- Cells are usually separated into lobules by fibrous septa.

- Devoid of significant mitotic activity, cellular pleomorphism, necrosis or myxoid change.

- Can have brown discoloration and central necrosis if pedunculated.

- Fibrous component can be very prominent.

Angiomatous type 
- Contains many thin-walled blood vessels.

- Typically found in mice.

Differential diagnoses

Hyperplasia, adipose tissue

- Is a diffuse change with little or no nodularity.

Hibernoma

- Typically contains multivesicular brown fat cells with centrally located nuclei.

Liposarcoma

- Shows histological features of malignancy such as pleomorphic spindle cells, mitotic activity and the presence of malignant lipoblasts.

Angioma

- Typically devoid of intercellular fat cells

Comment: Subcutaneous lipoma is a rare tumor in mice although lipomas of the brain are more common. These may represent lipomatous hamartomas rather than true neoplasms. Intracranial lipomas may my present in the interstitium of the choroid plexus. Lipomas have been induced in the subcutaneous tissues of rats treated with peroxisome proliferator-activated receptor (PPAR) agonists (Hardisty et al. 2007).

Hibernoma (B) (Figures 16-18): Soft Tissue

Species: Mouse, Rat

Synonym: Brown fat tumor

Diagnostic features

- Lobulated pale yellowish mass in posterior thoracic or abdominal region or within the mediastinum.

- Fairly uniform rounded cells with abundant fine cytoplasmic lipid droplets and central, round nuclei.

- Mitotic activity and cellular pleomorphism usually low.

\section{Differential diagnoses}

Liposarcoma

- Histological features of malignancy such as pleomorphic spindle cells, mitotic activity and the presence of malignant lipoblasts.

Comment: These are very characteristic tumors showing brown fat differentiation. Tumor cells are round oval or polygonal with dense rounded central nuclei. The foamy cytoplasm stains with oil red O. Electron microscopic study shows numerous mitochondria and small lipid droplets. They are rare tumors in all species including humans but they appear to be more commonly reported in rats (Coleman 1980; Al Zubaidy and Finn 1983; Stefanski et al. 1987; Coleman 1989; Bruner et al. 2009). A recent report has shown an increase in incidence in a colony of Sprague-Dawley rats (Bruner et al. 2009). These tumors can be stained immunocytochemically using antisera to mitochondrial uncoupling protein (UCP-1), a protein essential for the thermogenic properties of brown fat in mammals (Bruner et al. 2009).

Liposarcoma (M) (Figure 19): Soft Tissue

Species: Mouse, Rat

Diagnostic features

- Fatty mass of variable appearance.

- Rounded or oval fat-forming cells with single large or multiple small cytoplasmic fat vacuoles, spindle cells, primitive undifferentiated cells

- Cellularity and mitotic activity variable

- Myxoid change may be prominent in stroma.

- Necrosis may be marked.

Differential diagnoses

Lipoma

- Shows no evidence of pleomorphic spindle cells, malignant lipoblasts or significant mitotic activity.

Comment: Liposarcoma is characterized by the presence of fat forming cells, termed lipoblasts. These can be primitive mesenchymal cells with fine lipid droplets, larger rounded or oval cells with large central or eccentric nuclei and large cytoplasmic fat vacuoles. Various other cell types occur including 'brown' fat cells, foam cells, giant cells, myxoid cells and spindle and stellate cells. The stroma is usually well vascularized and a myxoid appearance may be evident and sometimes extensive (Greaves and Barsoum 1990). Undifferentiated cells also can be found and mitotic activity can be intense. Rapidly growing liposarcomas frequently have zones of necrosis. These are uncommon spontaneous neoplasms in rats and mice but have been induced along with fibrosarcomas in rats treated with peroxisome proliferator-activated receptor (PPAR) agonists (Hardisty et al. 2007; Long et al. 2009).

Rhabdomyosarcoma (M) (Figures 20 and 21): Soft Tissue

Species: Mouse, Rat

Diagnostic features

- Mass frequently showing necrosis and hemorrhage.

- Highly pleomorphic with rhabdomyoblasts, immature spindle and strap-like cells, mononucleated, rounded and polygonal cells.

- Rhabdomyoblasts characterized by eosinophilic fibrillar cytoplasm with myofilaments, glycogen inclusions, cross striations, immunocytochemical staining for myoglobin and ultrastructural evidence of $\mathrm{Z}$ bands.

- High mitotic activity with abnormal mitotic figures.

- Locally infiltrative with frequent distant metastases.

Differential diagnoses

Fibrosarcoma, pleomorphic 
- Shows no evidence of skeletal muscle differentiation.

Leiomyosarcoma:

- Generally less pleomorphic and show immune reactivity for desmin and smooth muscle actin.

Comment: The diagnosis of rhabdomyosarcoma depends on the histological identification of rhabdomyoblasts. These are characterized by the presence of eosinophilic cytoplasm, perinuclear fibrillar material, cross striations, glycogen, myofilaments well-stained with PTAH, immunoreactivity for desmin and myoglobin. At the ultrastructural level, they show cytoplasmic $\mathrm{Z}$ lines. They are uncommon spontaneously developing neoplasms in rodents. In the National Toxicology Program less that $0.2 \%$ of Fischer 344 rats developed this neoplasm (NTP 2006). Only 14 rhabdomyosarcomas were diagnosed at necropsy in 10,000 mice in one study, most often originating in the quadriceps muscles with a mean age of 4 months (Sundberg et al. 1991). They have been induced in rodents by injection nickel sulphide, monocrotaline or its major metabolite, dehydnonetronecine (Allen et al. 1975; Altmannsberger et al. 1985). Rhabdomyosarcomas have also been reported to develop around inert implants or repeated subcutaneous injection of iron dextran or other poorly absorbed substances (Oppenheimer et al. 1958; Carter 1970).

Leiomyoma (B): Soft Tissue

Species: Mouse, Rat

Diagnostic features

- Well circumscribed, nodular mass.

- Interlacing bundles and whorls of uniform spindle cells arranged in criss-cross patterns of bundles.

- Nuclei typically blunt-ended or cigar shaped.

- Eosinophilic cytoplasm contains longitudinal myofilaments and perinuclear clear space and show immunoreactivity for desmin.

- Minimal mitotic activity and nuclear pleomorphism.

Differential diagnoses

Leiomyosarcoma

- Shows mitotic activity and cellular pleomorphism.

Fibrosarcoma

- Shows mitotic activity and cellular pleomorphism but not discernible smooth muscle differentiation.

Comment: Benign tumors of smooth muscle are uncommonly found in the soft tissues of rodents. Most have been described in the uterus. They are well-circumscribed, nodular tumors characterized histologically by interlacing bundles of uniform spindle cells with typically blunt ended or cigar shaped nuclei. The cell cytoplasm may contain perinuclear clear spaces. Myofibrils are characteristically demonstrable as linear streaks which stain blue with phosphotungstic acid hematoxylin (PTAH) and red by Masson trichrome stain. Mitotic activity and nuclear pleomorphism are minimal. These neoplasms show immunocytochemical staining for desmin and smooth muscle actin. However, desmin may be also present in sarcomas of other subtypes (Hardisty et al. 2007).

Ultrastructural features include a cytoplasm packed with thin filaments with focal densities, some mitochondria, sparse profiles of endoplasmic reticulum and a Golgi apparatus situated adjacent to nuclear poles, micropinocytic vesicles and dense plaques at the points of attachment of myofilaments to the cell membrane. A poorly developed basal lamina may be present.

Leiomyosarcoma (M) (Figure 22): Soft Tissue

Species: Mouse, Rat

Diagnostic features

- Similar to leiomyoma but more pleomorphic and with mitotic activity.

- Interlacing bundles and whorls of spindle cells arranged in criss-cross patterns of bundles.

- Nuclei typically blunt-ended or cigar shaped

- Bizarre polygonal cells with double or multiple nuclei may be present

- Necrosis, cystic change, mineralization common features.

- Distant metastases.

Differential diagnoses

Leiomyoma

- Shows little or no cellular pleomorphism or mitotic activity.

Fibrosarcoma

- Devoid of smooth muscle differentiation.

Rhabdomyosarcoma

- Shows skeletal muscle differentiation.

Comment: This neoplasm is similar to the leiomyoma but it is invasive and shows mitotic activity and marked cellular pleomorphism. Bizarre polygonal cells with double or multiple nuclei as well as vacuolated cytoplasm may be present. Longitudinal myofibrils are demonstrable using the phosphotungstic acid hematoxylin (PTAH) stain. There are varying degrees of vascularity and abundant reticulin fibers run parallel to the tumour cells. Cellular pleomorphism, necrosis, cystic degeneration, mineralization and distant metastases are also typical features. However, the distinction between fibrosarcoma and leiomyosarcoma is not always clear cut. These are uncommon tumors in the soft tissues but are reported to develop occasionally in rodents around implanted biomaterials (Kirkpatrick et al. 2000). 
Mesenchymoma, malignant (M): Soft Tissue

Species: Mouse, Rat

Synonym: Mixed sarcoma.

Diagnostic features

- Mesenchymal tumor showing two or more types of mesenchymal differentiation in addition to fibrosarcomatous elements.

Differential diagnoses

- Sarcomas showing only one type of mesenchymal differentiation (Fibrosarcoma, Fibrosarcoma, pleomorphic, Liposarcoma, Rhabdomyosarcoma, Leiomyosarcoma).

Comment: This term is used for those rare tumors characterized by two or more differentiated mesenchymal tissue types such as fat, muscle, bone or cartilage in addition to undifferentiated or fibrosarcomatous elements. Electron microscopy or immunocytochemistry may be required to establish the presence of skeletal muscle differentiation in such tumors.

Sarcoma, NOS (Not otherwise specified) (M): Soft Tissue

Species: Mouse, Rat

Diagnostic features

- Mesenchymal tumor composed of sheets of undifferentiated round, spindle or pleomorphic cells.

- No recognizable light microscopic differentiation.

- Electron microscopy and immunocytochemistry can sometimes lead to accurate diagnosis.

- Not all sarcomas have distinguishing features even with ultrastructural or immunohistochemical study.

Differential diagnoses

- Sarcomas showing focal differentiation of a specific cell type type (Fibrosarcoma, Fibrosarcoma, pleomorphic, Liposarcoma, Rhabdomyosarcoma, Leiomyosarcoma).

Comment: In view of the potential variety of histological appearances of neoplasms of mesenchymal cells, it may not always be possible to make a precise diagnosis of all soft tissue tumors, particularly without ultrastructural examination or a battery of appropriate antisera for immunocytochemical demonstration of antigens. It is appropriate to classify such neoplasms as sarcoma, NOS.

Mesothelioma, malignant (M) (Figures 23 and 24): Mesothelium

Species: Mouse, Rat

Modifier: Epithelioid type, Sarcomatoid type, Biphasic type.

Diagnostic features

- Predominantly superficial growth of tumor on the serosal surface where cells usually show considerable cellular pleomorphism, mitotic activity, necrosis and infiltration of adjacent tissues.

Epithelioid type

- Fronds or papillary structures.

- Poorly formed glandular structures or ill-formed glands.

- Rounded cells with round vesicular nuclei.

- Infiltration into adjacent connective tissue.

Sarcomatoid type

- Relatively uniform spindle-shaped cells with elongated nuclei.

- Interlacing bundles similar to fibrosarcomas or leiomyosarcomas or forming whorls suggestive of pleomorphic sarcomas (malignant fibrous histiocytomas).

- Areas resembling osteosarcoma, chondrosarcoma or other sarcomas may be present (Rittinghausen et al. 1992; Cardesa et al. 1994).

Biphasic type

- Contains both epithelioid and sarcomatoid patterns.

- Any patterns noted above may be present. Each component should represent at least $10 \%$ of the tumor

Differential diagnoses

Metastatic tumors:

- Presence of primary tumor with similar morphologic characteristics.

The differentiation between sarcomatoid forms and other sarcoma types may be difficult without special techniques.

Fibrosarcoma

- May show a similar spindle cell appearance. Without special stains it may be difficult to distinguish spindle cell fibrosarcomas arising in soft tissues from sarcomatoid mesotheliomas particularly when they large and the site of origin unclear.

Thymoma

- Localized thoracic mass with highly variable epithelial patterns usually interspersed with lymphoid tissue.

Extension of primary lung malignancies into thoracic cavity

- Presence of microscopic evidence of tumor extension into pleura, and similar histological patterns in extended tumor mass.

Hyperplasia, mesothelium

- Lack of evidence of mitotic activity, cellular atypia, or extension into adjacent tissues. Usually focal thickening or villous projections with cellular stratification. It may be accompanied by inflammation.

Comment: Desmoplastic areas characterized by dense collagenous tissue separated by atypical cells may occur in all types of mesothelioma.

Pleural and peritoneal cavity mesotheliomas are rare 
spontaneous lesions in rodents but have been induced in rats, mice and hamsters by a number of persistent fibrous materials or by other xenobiotics like potassium-bromate (Schwartz et al. 1994; Crosby et al. 2000; Kane 2006; Takagi et al. 2008; Maronpot et al. 2009; Sakamoto et al. 2009; Bernstein et al. 2010; Donaldson et al. 2010). Although a body of evidence suggests that SV40 might be one causative agent of malignant mesothelioma in humans this remains a contentious issue (von Ruhland et al. 2004).

The morphology of this tumor is similar in rats and humans (Travis et al. 2004). Differentiation of pleural mesotheliomas from primary lung carcinomas can be difficult. They not only occur in the pleural cavity or pericardium but also the peritoneum. One of the most frequent sites in the rat is the tunica vaginalis of the testis from which they may spread to the peritoneal cavity (McConnell et al. 1992). Spontaneous, as well as several, xenobiotic-associated tunica vaginalis me- sotheliomas are causally associated with Leydig-cell tumors that lead to an autocrine growth factor-induced mesothelial mitogenesis (Maronpot et al. 2009).

For epithelioid mesothelioma, the most useful markers are broad spectrum cytokeratin, cytokeratin 5/6, cytokeratin 18, Wilm's Tumor-gene 1 WT1 and calretinin (Kane 2006; Maronpot et al. 2009). Mesothelin is also considered to be a reliable marker (Doi et al. 2010). Most sarcomatoid mesotheliomas typically stain positively for cytokeratin when a broad-spectrum antibody is used. They may stain positively for vimentin, smooth muscle actin, desmin, or S-100.

Mesotheliomas uncommonly exhibit positive mucin staining, when combined diastase and periodic acidSchiff (D-PAS) is used. A diffuse strongly positive D-PAS in an epithelioid pleural tumor is strongly suggestive of pulmonary bronchiolo-alveolar carcinoma, whilst weak or focal staining is of less diagnostic value. 



Figure 1. - A) Lesion from the face of a Wistar rats with marked inflammation and abscess formation and development of a fibrous capsule (H\&E). The abscess contains much cellular debris including gram positive bacteria seen in B) (Gram stain).

Figure 2. - Other examples of chronic inflammation in connective tissue. In A) there is a dense chronic inflammatory infiltrate composed of mononuclear cells which occurred in response to injected pigment seen here as black fragments. In B) the tissues show no necrosis but contain a sparse scattering of chronic inflammatory cells with a vascular proliferative response (H\&E).

Figure 3. - Mesenteric fat from a C67Bl mouse fed a high fat diet. There is a granulomatous inflammatory process in the fat with clusters of macrophages with lipid vacuoles and brown lipofuscin pigment (H\&E).

FIGURE 4. - A) Mesenteric fat from a B6C3F1 mouse showing a large nodule of fat necrosis in which the acellular necrotic fat cells can be seen surrounded by a thin rim of poorly cellular connective tissues (H\&E). Image by courtesy of the National Toxicology Program. B) Subcutaneous tissue from a Wistar rat treated with a novel drug that produced fat necrosis. This shows acute damage. 

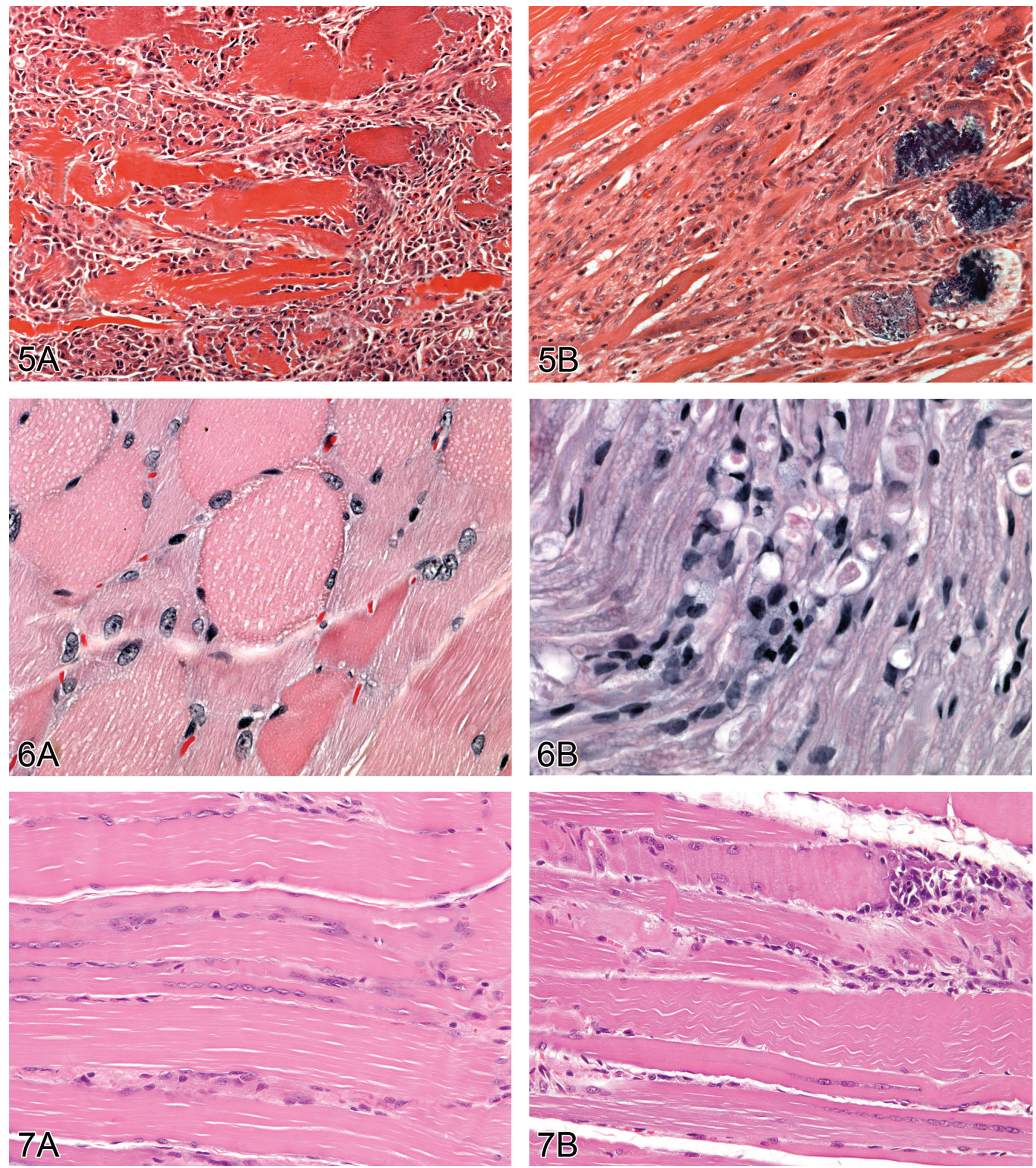

FIGURE 5. - Muscle showing the stereotypical necrosis and repair response four A) and 10 days B) following a single injection of the local anesthetic lignocaine. Mineralisation of muscle fibers is apparent at 10 days (H\&E).

FIGURE 6. - In A) there is muscle degeneration due to spinal nerve compromise in an aged rat. B) shows section of spinal nerve showing degenerative alterations to nerve fibres (H\&E).

FIGURE 7. - Skeletal muscle from thigh of a Sprague Dawley rat treated for 3 months with a peroxisomal proliferator (WY-14643) showing a degenerative form of myopathy. In A) there focal inflammation associated with muscle fiber necrosis characterised by cytoplasmic eosinophilia and loss of cytoplasmic structure. In B) typical reparative response is seen with numerous central nuclei being visible in fibers that are variable in thickness (H\&E). Images by courtesy of the National Toxicology Program. 



FigURE 8. - Quadriceps muscle from a Wistar rat treated with a novel therapeutic agent drug that produce mild muscle degeneration associated with a chronic inflammatory infiltrate seen in this view (H\&E).

Figure 9. - Spontaneous focal muscle fiber necrosis in a 2 year old C57Bl mouse. An intact muscle fiber is seen adjacent to a necrotic fiber with an early cellular response (H\&E).

FigURE 10. - A) Subcutaneous fibroma from a mouse showing homogenous fibrous structure with overlying epidermis. B) Higher power view of fibroma seen in A) shows paucity of fibroblastic cells (H\&E).

FigURE 11. - Two examples of rat fibromas. A) poorly cellular tumour with abundant dense eosinophilic bands of collagen ( H\&E, bar $=100 \mu \mathrm{m})$. B) also poorly cellular but with a loose pale-staining myxoid stroma (H\&E). 

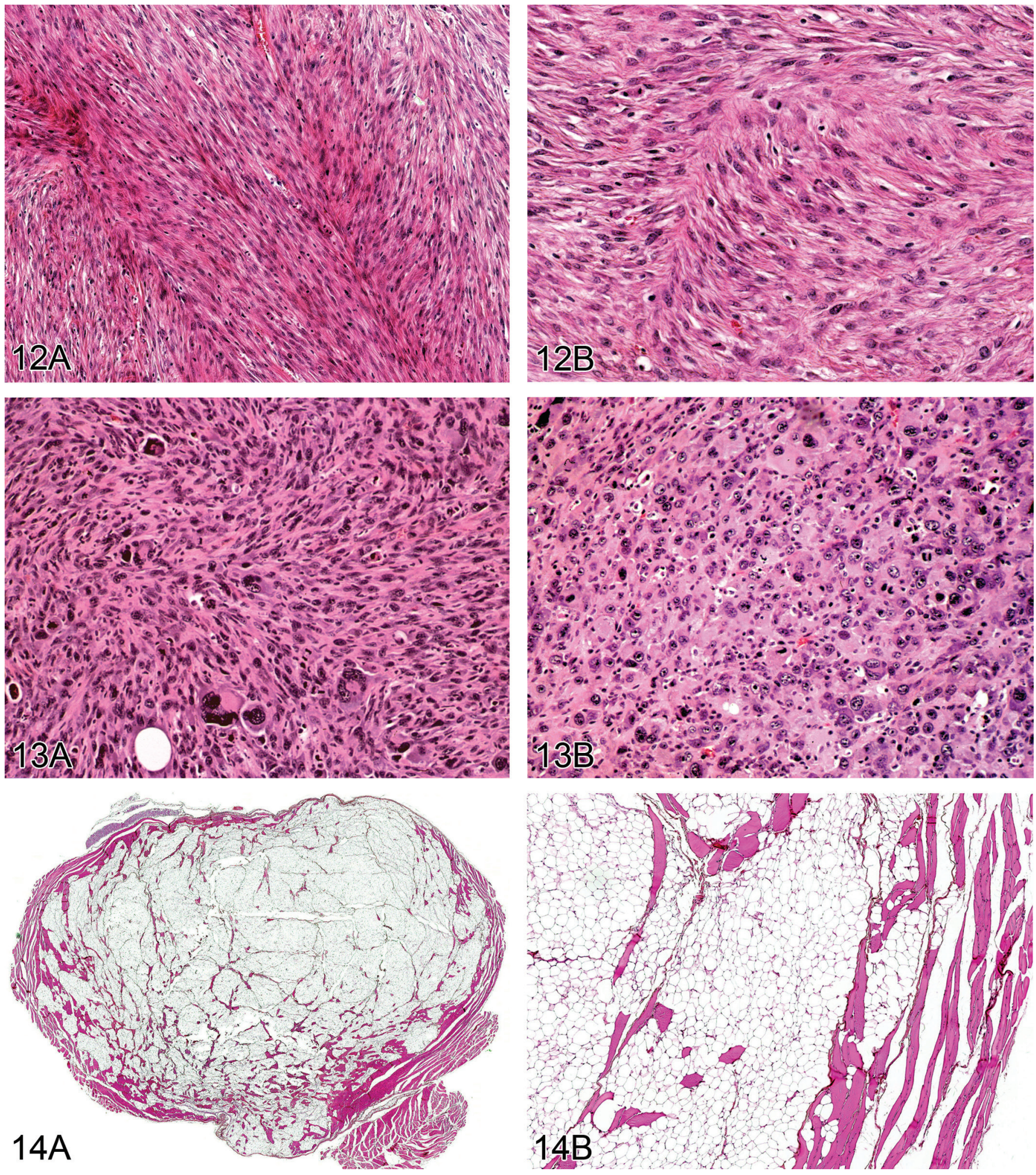

FiguRE 12. - A) A well differentiated fibrosarcoma from a rat. (H\&E, bar $=100 \mu \mathrm{m})$. In B) the fairly cellular appearance composed of fine spindle cells exhibiting relatively little nuclear pleomorphism can be seen $(\mathrm{H} \& \mathrm{E})$

FiguRE 13. - Pleomorphic fibrosarcoma induced by implanted foreign bodies in Sprague Dawley rats. A) and B) show the range of histological features of this type of neoplasm: spindle cells, plump cells, multinucleated cells and bizarre cells (H\&E).

FiguRE 14. - Lipoma from a rat. A) Low power view of a round nodule of near normal fat cells partially surrounded by a thin fibrous capsule. B) Higher power view showing cellular detail (H\&E). 

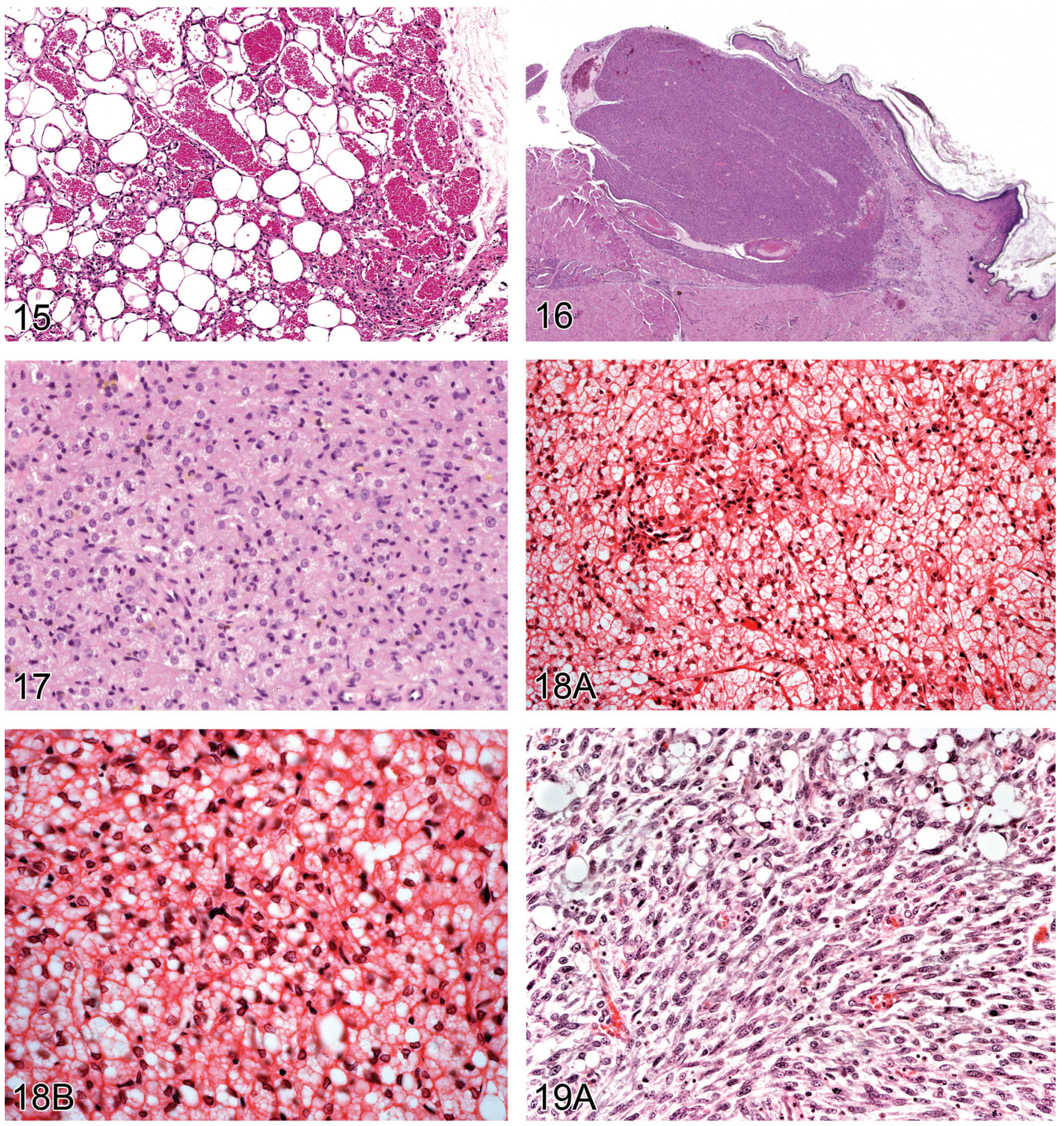

FigURE 15. - Lipoma of angiomatous type from a rat containing numerous thin walled blood vessels (H\&E).

FIGURE 16. - Subcutaneous hibernoma from a B6C3F1 mouse (H\&E). Image by courtesy of the National Toxicology Program.

Figure 17. - Higher power view of tumor in Figure 16 showing cellular detail, notably the dense eosinophilic staining cytoplasm (H\&E). Image by courtesy of the National Toxicology Program.

FiguRE 18. - A) and B) low and high power view of hibernoma from the thorax from an aged Wistar rat showing pale staining foamy cytoplasm (H\&E).

Figure 19. - Liposarcoma from an aged Wistar rat. A) Shows spindle cells and fat containing cells. 

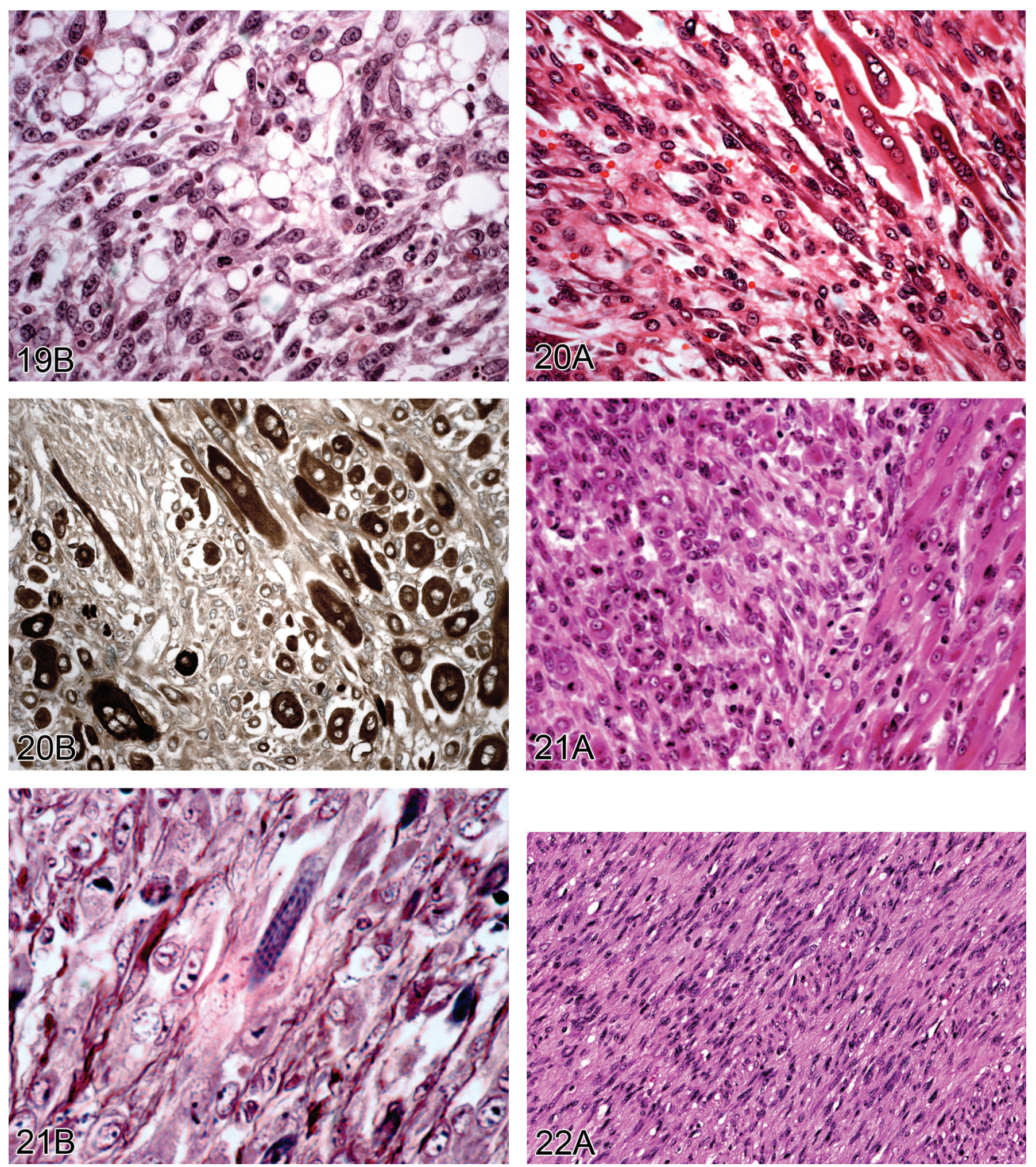

FIGURE 19. - Liposarcoma from an aged Wistar rat. B) Higher power view showing atypical fat forming cells (lipoblasts) (H\&E).

FIGURE 20. - Well-differentiated rhabdomysarcoma from a Wistar rat. A) Tumor cells showing good muscle differentiation (H\&E). B) Same tumor stained for myoglobin (Immunoperoxidase).]

Figure 21. - Rhabdomyosarcoma from a CD1 mouse (H\&E). A) Well differentiated tumor cells. B) Shows cross striations confirming muscle differentiation $(\mathrm{PTAH})$. 

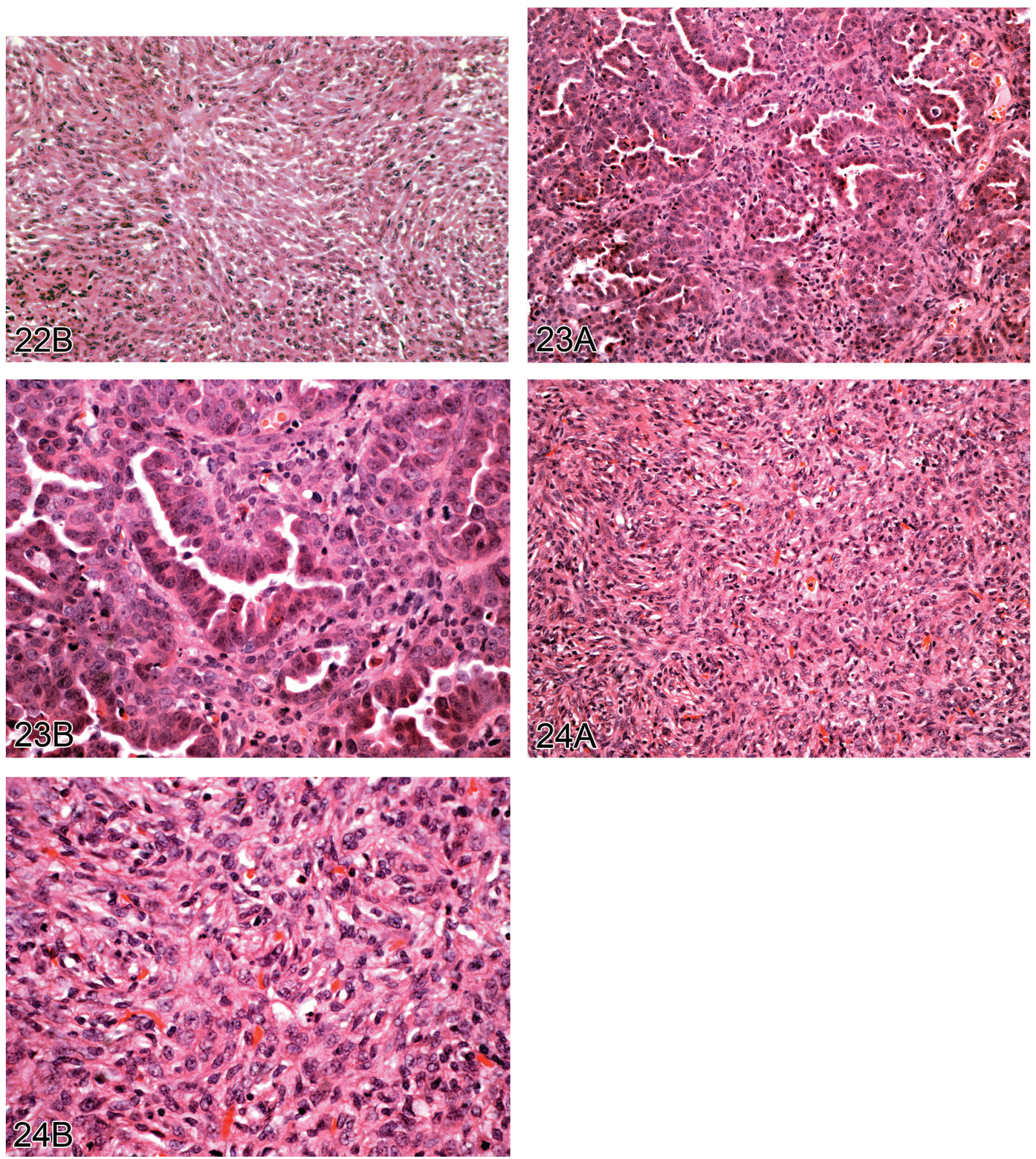

FIGURE 22. - A) Well differentiated leiomyosarcoma from a rat showing interwoven bundles of spindle cells with typical oval shaped nuclei of smooth muscle. B) Another example of a leiomyosarcoma but showing clear muscle differentiation (H\&E).

Figure 23. - A) Low and B) high power view of mesothelioma of epithelioid type which developed in the pleura of a rat in response to the administration of fine fibers (H\&E).

FIGURE 24. - A) Low and B) high power view of mesothelioma of sarcomatoid type which developed in the pleura of a rat in response to the administration of fine fibers $(\mathrm{H} \& \mathrm{E})$. 


\section{REFERENCES}

Al Zubaidy AJ, and Finn JP. Brown fat tumors (hibernomas) in rats: Histopathological and ultrastructural study. Lab Anim. 17: 13-17. 1983.

Allen JR, Hsu IC, and Carstens LA. Dehydroretronecine-induced rhabdomyosarcomas in rats. Cancer Res. 35(4): 997-1002. 1975.

Altmannsberger M, Weber K, Droste R, and Osborn M. Desmin is a specific marker for rhabdomyosarcomas of human and rat origin. Am J Pathol. 118(1): 85-95. 1985.

Anderson JM, and Langone JJ. Issues and perspectives on the biocompatibility and immunotoxicity evaluation of implanted controlled release systems. J Control Release. 57(2): 107-113. 1999.

Autian J. The new field of plastics toxicology - methods and results. CRC Crit Rev Toxicol. 2: 1-40. 1973.

Behan WMH, Cossar DW, Madden HA, and McKay IC. Validation of a simple, rapid, and economical technique for distinguishing type 1 and 2 fibres in fixed and frozen skeletal muscle. J Clin Pathol. 55(5): 375-380. 2002.

Bernstein DM, Rogers RA, Sepulveda R, Donaldson K, Schuler D, Gaering S, Kunzendorf P, Chevalier J, and Holm SE. The pathological response and fate in the lung and pleura of chrysotile in combination with fine particles compared to amosite asbestos following short-term inhalation exposure: interim results. Inhal Toxicol. 22(11): 937-962. 2010.

Blanchard KT, Barthel C, French JE, Holden HE, Moretz R, Pack FD, Tennant RW, and Stoll RE. Transponder-induced sarcoma in the heterozygous p53(+/-) mouse. Toxicol Pathol. 27(5): 519-527. 1999.

Boorman GA, Eustis SL, and Elwell MR. (1989). Fibrosarcoma, dermis and subcutis, mouse. Monographs on Pathology of Laboratory Animals, Integument and Mammary Glands. T. C. Jones, U. Mohr and R. D. Hunt. Berlin, Springer: 95-100.

Bradley WG, Fewings JD, Harris JB, and Johnson MA. Emetine myopathy in the rat. Br J Pharmacol. 57: 29-41. 1976.

Brand KG, Johnson KH, and Buoen LC. Foreign body tumorigenesis. CRC Crit Rev Toxicol. 4: 353-394. 1976.

Brooke MH, and Kaiser KK. Muscle fiber types: How many and what kind? Arch Neurol. 23: 369-379. 1970.

Brooke MH, Williamson E, and Kaiser KK. The behaviour of four fiber types in developing and reinnervated muscle. Arch Neurol. 25: 360-366. 1971.

Bruner RH, Novilla MN, Picut CA, Kirkpatrick JB, O’Neill TP, Scully KL, Lawrence WB, Goodman DG, Saladino BH, Peters DG, and Parker GA. Spontaneous hibernomas in Sprague-Dawley rats. Toxicol Pathol. 37(4): 547-552. 2009.

Cardesa A, Carlton WW, Dungworth DL, Enomoto Y, Halm S, Koestner A, Krinke GJ, Render JA, Rittinghausen S, Ruben Z, Solleveld H, Turusov VS, Weisse I, and Yoshitomi K. Central nervous system; heart; eye; mesothelium. International Classification of Rodent Tumours. Part 1 The Rat. U. Mohr. Lyon, International Agency for Research on Cancer. IARC Sci Pub. 7(122): 61-65. 1994.

Carlton, W. W., Ernst, H., Faccini, J. M., Greaves, P., Krinke, G. J., Long, P. H., Maekawa, A., Newsholme, S. J., and G. W. (1992). Soft tissue and musculoskeletal system, 2. Part 1. International Classification of Rodent Tumours. U. Mohr. Lyon, International Agency for Research on Cancer.

Carter RL. (1970). Induced subcutaneous sarcomata: Their development and critical appraisal. Metabolic Aspects of Food Safety. F. J. C. Roe. Oxford, Blackwell: 569-591.

Carter RL, Roe FJC, and Peto R. Tumor induction by plastic films: Attempt to correlate carcinogenic activity with certain physiochemical properties of the implant. J Natl Cancer Inst. 46: 1277-1289. 1971.

Chesterman FC, Harvey JJ, Dourmashkin RR, and Salaman MH. The Pathology of tumors and other lesions induced in rodents by virus derived from a rat with Moloney leukemia. Cancer Res. 26(8): 1759-1768. 1966.

Clarke JTR, Karpati G, Carpenter S, and Wolfe LS. The effect vincristine on skeletal muscle in the rat. A correlative histochemical, ultrastructural and chemical study. J Neuropathol Exp Neurol. 31: 247-266. 1972.

Coindre JM, Terrier P, Guillou L, Le Doussal V, Collin F, Ranchere D, Sastre $\mathrm{X}$, Vilain MO, Bonichon F, and Bui BN. Predictive value of grade for metastasis development in the main histologic types of adult soft tissue sarcomas - A study of 1240 patients from the French Federation of Cancer Centers Sarcoma Group. Cancer. 91(10): 1914-1926. 2001.

Coleman GL. Four intrathoracic hibernomas in rats. Vet Pathol. 17: 634-637. 1980.

Coleman GL. (1989). Hibernoma, rat. Integument and Mammary Glands, Monographs on Pathology of Laboratory Animals. T. C. Jones, U. Mohr and R. D. Hunt. Berlin, Springer-Verlag: 126-129.

Crosby LM, Morgan KT, Gaskill B, Wolf DC, and DeAngelo AB. Origin and distribution of potassium bromate-induced testicular and peritoneal mesotheliomas in rats. Toxicol Pathol. 28(2): 253-266. 2000.

Danse BHJC. (1989). Steatitis, subcutaneous tissue and generalised, rat. Monographs on Pathology of Laboratory Animals. Integument and Mammary Glands. T. C. Jones, U. Mohr and R. D. Hunt. Berlin, Springer-Verlag: 146-152.

De Souza AT, Cornwell PD, Dai XD, Caguyong MJ, and Ulrich RG. Agonists of the peroxisome proliferator-activated receptor alpha induce a fibertype-selective transcriptional response in rat skeletal muscle. Toxicol Sci. 92(2): 578-586. 2006.

Dincer Z, Jones S, and Haworth R. Preclinical safety assessment of a DNA vaccine using particle-mediated epidermal delivery in domestic pig, minipig and mouse. Exp Toxicol Pathol. 57(5-6): 351-357. 2006.

Dinse GE, Peddada SD, Harris SF, and Elmore SA. Comparison of NTP historical control tumor incidence rates in female Harlan Sprague Dawley and Fischer 344/N rats. Toxicol Pathol. 38(5): 765-775. 2010.

Doi T, Kotani Y, Takahashi K, Hashimoto S, Yamada N, Kokoshima H, Tomonari Y, Wako Y, and Tsuchitani M. Malignant mesothelioma in the thoracic cavity of a $\mathrm{Crj}: \mathrm{CD}(\mathrm{SD})$ rat characterized by round hyalinous stroma. J Toxicol Pathol. 23(2): 103-106. 2010.

Donaldson, K., Murphy, F. A., Duffin, R., and Poland, C. A. (2010). Asbestos, carbon nanotubes and the pleural mesothelium: a review of the hypothesis regarding the role of long fibre retention in the parietal pleura, inflammation and mesothelioma. Particle and Fibre Toxicology 7: Article No.: 5.

Eddinger TJ, Moss RL, and Cassens RG. Fiber number and type composition in extensor digitorum longus, soleus, and diaphragm muscles with ageing in Fischer 344 rats. J Histochem Cytochem. 33: 1033-1041. 1985.

Eiben R. Frequency and time trends of spontaneous tumors found in $\mathrm{B} 6 \mathrm{C} 3 \mathrm{~F}(1)$ mice oncogenicity studies over 10 years. Exp Toxicol Pathol. 53(5): 399408. 2001.

Elcock LE, Stuart BP, Wahle BS, Hoss HE, Crabb K, Millard DM, Mueller RE, Hastings TF, and Lake SG. Tumors in long-term rat studies associated with microchip animal identification devices. Exp Toxicol Pathol. 52(6): 483-491. 2001.

Ernst H, Carlton WW, Courtney C, Rinke M, Greaves P, Isaacs KR, Krinke G, Konishi Y, Mesfin GM, and Sandusky G. (2001). Soft tissue and skeletal muscle. Heidelberg, Springer Verlag.

Everitt AV, Shorey CD, and Ficarra MA. Skeletal muscle ageing in the hind limb of the old male Wistar rat: inhibitory effect of hypophysectomy and food restriction. Arch Gerontol Geriat. 4: 101-115. 1985.

Faccini JM, Abbott DP, and Paulus GJJ. (1990). Mouse Histopathology. A glossary for use in toxicity and carcinogenicity studies. Amsterdam, Elsevier.

Faiola B, Falls JG, Peterson RA, Bordelon NR, Brodie TA, Cummings CA, Romach EH, and Miller RT. PPAR alpha, more than PPAR delta, mediates the hepatic and skeletal muscle alterations induced by the PPAR agonist GW0742. Toxicol Sci. 105(2): 384-394. 2008.

Fletcher CDM. Malignant fibrous histiocytoma? Histopathology. 11: 433437. 1987.

Fletcher CDM. The evolving classification of soft tissue tumours: an update based on the new WHO classification. Histopathology. 48(1): 3-12. 2006.

Flint OP, Noor MA, Hruz PW, Hylemon PB, Yarasheski K, Kotler DP, Parker $\mathrm{RA}$, and Bellamine A. The role of protease inhibitors in the pathogenesis of HIV-associated lipodystrophy: Cellular mechanisms and clinical implications. Toxicol Pathol. 37(1): 65-77. 2009.

Floyd E, Mann P, Long G, and Ochoa R. The Trp53 hemizygous mouse in pharmaceutical development: Points to consider for pathologists. Toxicol Pathol. 30(1): 147-156. 2002.

Garg A. Acquired and inherited lipodystrophies. New Engl J Med. 350(12): 
$1220-1234.2004$.

Gopinath C, and Gibson WA. Mesovarian leiomyomas in the rat. Environ Health Perspect. 73: 107-113. 1987.

Grasso P, and Goldberg L. Early changes at the site of repeated subcutaneous injections of food colorings. Food Cosmet Toxicol. 4: 269-282. 1966 a.

Grasso P, and Goldberg L. Subcutaneous sarcoma as an index of carcinogenic potency. Food Cosmet Toxicol. 4: 297-320. 1966b.

Greaves P. (2012). Skeletal Muscle. Histopathology of Preclinical Toxicity Studies. Fourth Edition. Amsterdam, Academic Press/Elsevier: 180-206.

Greaves, P., and Barsoum, N. (1990). Pathology of tumours in laboratory animals. Tumours of the rat. Tumours of soft tissues. IARC Scientific(99): 597-623.

Greaves, P., Carlton, W. W., Courtney, C. L., Ernst, H., Halm, S., Isaacs, K. R., Konishi, Y., Krinke, G. J., Mesfin, S. G., Rinke, M., and Sandusky, G. (2000). Proliferative and non-proliferative lesions of soft tissues and skeletal muscle in mice. Guides for Toxicologic Pathology. Washington DC, STP/ARP/AFIP. MSTM-1.

Greaves P, and Faccini JM. Spontaneous fibrous histiocytic neoplasms in rats. Brit J Cancer. 43(3): 402-411. 1981.

Greaves, P., Faccini, J. M., and Courtney, C. L. (1992). Proliferative lesions of soft tissues and skeletal muscle in rats. Guides for Toxicologic Pathology. Washington DC, STP/ARP/AFIP. MST-1.

Greaves, P., and Seely, J. C. (1996). Non-proliferative lesions of soft tissues and skeletal muscle in rats. Guides for Toxicologic Pathology. Washington DC, STP/ARP/AFIP. MST-1.

Hahn FF, Guilmette RA, and Hoover MD. Implanted depleted uranium fragments cause soft tissue sarcomas in the muscles of rats. Environ Health Perspect. 110: 51-59. 2002.

Haines DC, Chattopadhyay S, and Ward JM. Pathology of aging B6;129 mice. Toxicol Pathol. 29(6): 653-661. 2001.

Hajdu SI. (1986). Histogenesis and classification. In: Differential Diagnosis of Soft Tissue and Bone Tumours. Philadelphia, Lea and Febiger: 3-34.

Hardisty JF, Elwell MR, Ernst H, Greaves P, Kolenda-Roberts H, Malarkey DE, Mann PC, and Tellier PA. Histopathology of hemangiosarcomas in mice and hamsters and liposarcomas/fibrosarcomas in rats associated with PPAR agonists. Toxicol Pathol. 35: 928-941. 2007.

Heider K, and Eustis SL. (1994). Tumours of the soft tissues. Pathology of Tumours in Laboratory Animals. Tumours of the Mouse, 2nd Edition. V. S. Turusov and U. Mohr. Lyon, IARC Scientific Publ. 111. 2: 611-649.

Hinz B. The myofibroblast: Paradigm for a mechanically active cell. J Biomech. 43(1): 146-155. 2010.

Hooson J, Grasso P, and Gangolli SD. Injection site tumours and preceding pathological changes in rats treated subcutaneously with surfactants and carcinogens. Brit J Cancer. 27: 230-244. 1973.

Jaweed MM, Alleva FR, Herbison GJ, Ditunno JF, and Balazs T. Muscle atrophy and histopathology of the soleus in 6-mercaptopurine-treated rats. Exp Mol Pathol. 43: 74-81. 1985.

Kane AB. Animal models of malignant mesothelioma. Inhal Toxicol. 18(12): 1001-1004. 2006.

Keegan GM, Learmonth ID, and Case CP. A systematic comparison of the actual, potential, and theoretical health effects of cobalt and chromium exposures from industry and surgical implants. Crit Rev Toxicol. 38(8): 645-674. 2008

Kempson RL, Fletcher CDM, Evans HL, Hendrickson MR, and Sibley RK. (2001). Tumors of the Soft Tissues. Washington DC, Armed Forces Institute of Pathology.

Kirkpatrick CJ, Alves A, Kohler H, Kriegsmann J, Bittinger F, Otto M, Williams DF, and Eloy R. Biomaterial-induced sarcoma - A novel model to study preneoplastic change. Am J Pathol. 156(4): 1455-1467. 2000.

Konishi Y, Maruyama H, Mii Y, Miyauchi Y, Yokose Y, and Masuhara K. Malignant fibrous histiocytomas induced by 4-(hydroxyamino)quindine 1-oxide in rats. J Natl Cancer Inst. 68: 859-865. 1982.

Kouchi M, Okimoto K, Matsumoto I, Michimae Y, Yamada T, Inoue T, Kimura T, Seki T, Yasuba M, and Hino O. Postoperative fibromatosistype fibromas in the Bhd gene mutant (Nihon) rat. Exp Toxicol Pathol. 59(5): 273-279. 2008.

Larade K, Jiang ZG, Zhang YZ, Wang WF, Bonner-Weir S, Zhu H, and Bunn
HF. Loss of Ncb5or results in impaired fatty acid desaturation, lipoatrophy, and diabetes. J Biol Chem. 283(43): 29285-29291. 2008.

Le Calvez S, Perron-Lepage M-F, and Burnett R. Subcutaneous microchipassociated tumours in B6C3.F1 mice: A retrospective study to attempt to determine their histogenesis. Exp Toxicol Pathol. 57(4): 255-265. 2006.

Liu K, Tripp S, and Layfield LJ. Heterotopic ossification: Review of histologic findings and tissue distribution in a 10-year experience. Pathol Res Pract. 203(9): 633-640. 2007.

Liu ZJ, Zhuge Y, and Velazquez OC. Trafficking and differentiation of mesenchymal stem cells. J Cell Biochem. 106(6): 984-991. 2009.

Livingstone I, Johnson MA, and Mastaglia FL. Effects of dexamethasone on fibre subtypes in rat muscle. Neuropathol Appl Neurobiol. 7: 381-398. 1981.

Long GG, Reynolds VL, Dochterman LW, and Ryan TE. Neoplastic and nonneoplastic changes in F-344 rats treated with naveglitazar, a gamma-dominant PPAR alpha/gamma agonist. Toxicol Pathol. 37(6): 741-753. 2009.

Majeed, S. K. (1993). Survey on spontaneous systemic amyloidosis in aging mice. Arzneimittel-Forschung/Drug Research 43-1(2): 170-178.

Mann PC, Vahle J, Keenan CM, Baker JF, Bradley AE, Goodman DG, Harada T, Herbert R, Kaufmann W, Kellner R, Nolte T, Rittinghausen S, and Tanaka T. (2012). International Harmonization of Toxicologic Pathology Nomenclature: An overview and review of basic principles. Pre-publication.

Manor D, and Sadeh M. Muscle fibre necrosis induced by intramuscular injection of drugs. Br J Exp Pathol. 70: 457-462. 1989.

Maronpot RR, Zeiger E, McConnell EE, Kolenda-Roberts H, Wall H, and Friedman MA. Induction of tunica vaginalis mesotheliomas in rats by xenobiotics. Crit Rev Toxicol. 39(6): 512-537. 2009.

McClung JM, Mehl KA, Thompson RW, Lowe LL, and Carson JA. Nandrolone decanoate modulates cell cycle regulation in functionally overloaded rat soleus muscle. Am J Physiol-Regul Integr Comp Physiol. 288(6): R1543-R1552. 2005.

McConnell RF, Western HH, Ulland BM, Bosland MC, and Ward JM. (1992). Proliferative lesions of the testis in rats with selected examples from mice. Guides for Toxicologic Pathology. Washington DC, STP/ARP/AFIP.

McNamara A, and Williams DF. The response to the intramuscular implantation of pure metals. Biomaterials. 2: 33-40. 1981.

Miao CY, and Li ZY. The role of perivascular adipose tissue in vascular smooth muscle cell growth. Br J Pharmacol. 165(3): 643-658. 2012.

Morgan RW, and Elcock M. Artificial implants and soft-tissue sarcomas. $J$ Clin Epidemiol. 48(4): 545-549. 1995.

Munfus DL, and Menke DM. Case of severe serous fat atrophy. Mayo Clin Proc. 84(7): 570. 2009.

Mutsaers SE, Prele CM, Lansley SM, and Herrick SE. The origin of regenerating mesothelium: A historical perspective. Int J Artif Organs. 30: 484-494. 2007.

NTP NTP Historical Controls Report All Routes and Vehicles. Rats. Research Triangle Park, National Toxicology Program. National Institute of Environmental Health Sciences. 2006

Okada M, Inoue Y, Ube M, Sano F, Ikeda I, Sugimoto J, and Takagi S. Skeletal muscle susceptibility to clofibrate induction of lesions in rats. Toxicol Pathol. 35(4): 517-520. 2007.

Okada M, Sano F, Ikeda I, Sugimoto J, Takagi S, Sakai H, and Yanai T. Fenofibrate-induced muscular toxicity is associated with a metabolic shift limited to type-1 muscles in rats. Toxicol Pathol. 37(4): 517-520. 2009.

Oppenheimer BSC, Oppenheimer ET, and Stout AP. Carcinogenic effect of imbedding various plastic films in rat and mice. Surg Forum. 4: 672-676. 1953.

Oppenheimer BSC, Oppenheimer ET, Stout AP, Willhite M, and Danishefsky I. The latent period in carcinogenesis by plastics in rats and its relation to the presarcomatous stage. Cancer. 11: 204-213. 1958.

Oppenheimer ET, Willhite M, Stout AP, Danishefsky I, and Fishman MM. A comparative study of the effects of imbedding cellophane and polystyrene films in rats. Cancer Res. 24: 379-382. 1964.

Parrott E, Butterworth M, Green A, White INH, and Greaves P. Adenomyosis - A result of disordered stromal differentiation. Am J Pathol. 159(2): 623-630. 2001. 
Picha GJ, Goldstein JA, and Stohr E. Natural-Y Même polyurethane versus smooth silicone - analysis of the soft-tissue interaction from 3 days to 1 year in the rat animal-model. Plast Reconstr Surg. 85(6): 903-916. 1990.

Poteracki J, and Walsh KM. Spontaneous neoplasms in control Wistar rats: A comparison of reviews. Toxicol Sci. 45: 1-8. 1998.

Prot M, Heripret L, Cardot-Leccia N, Perrin C, Aouadi M, Lavrut T, Garraffo R, Dellamonica P, Durant J, Le Marchand-Brustel Y, and Binetruy B. Long-term treatment with lopinavir-ritonavir induces a reduction in peripheral adipose depots in mice. Antimicrob Agents Chemother. 50(12): 3998-4004. 2006.

Prysor-Jones RA, and Jenkins JS. Effect of excessive secretion of growth hormone on tissues of the rat, with particular reference to the heart and skeletal muscle. J Endocrinol. 85: 75-82. 1980.

Rittinghausen S, Ernst H, Muhle H, and Mohr U. Atypical malignant mesotheliomas with osseous and cartilaginous differentiation after intraperitoneal injection of various types of mineral fibers in rats. Exp Toxicol Pathol. 44(1): 55-58. 1992.

Roe FJC, and Carter RL. Iron-dextran carcinogenesis in rats: Influence of dose on the number of types of neoplasm induced. Int J Cancer. 2: 370380. 1967.

Sakamoto Y, Nakae D, Fukumori N, Tayama K, Maekawa A, Imai K, Hirose A, Nishimura T, Ohashi N, and Ogata A. Induction of mesothelioma by a single intrascrotal administration of multi-wall carbon nanotube in intact male Fischer 344 rats. J Toxicol Sci. 34(1): 65-76. 2009.

Schaefer WH, Lawrence JW, Loughlin AF, Stoffregen DA, Mixson LA, Dean DC, Raab CE, Yu NX, Lankas GR, and Frederick CB. Evaluation of ubiquinone concentration and mitochondrial function relative to cerivastatin-induced skeletal myopathy in rats. Toxicol Appl Pharmacol. 194(1): 10-23. 2004.

Schneider P, Busch U, Meister H, Qasem Q, and Wünsch PH. Malignant fibrous histiocytoma (MFH). A comparison of MFH in man and animals. A critical review. Histology amd. Histopathol. 14: 845-860. 1999.

Schwartz LW, Hahn FF, Keenan CM, Brown HR, and Mann PC. (1994). Proliferative lesions of the rat respiratory tract, R-1. Guides for Toxicologic Pathology. Washington DC, STP/ARP/AFIP.

Seiden D. Effects of colchicine on myofilament arrangement and the lysosomal system in skeletal muscle. Zeitschrift für Zellforschung und Mikroskopische Anatomie. 144: 467-483. 1973.

Sevastianova K, Sutinen J, Greco D, Sievers M, Salmenkivi K, Perttila J, Olkkonen VM, Wagsater D, Lidell ME, Enerback S, Eriksson P, Walker UA, Auvinen P, Ristola M, and Yki-Jarvinen H. Comparison of dorsocervical with abdominal subcutaneous adipose tissue in patients with and without antiretroviral therapy-associated lipodystrophy. Diabetes. 60(7): 1894-1900. 2011.

Shoieb A, Allavena R, Swallow J, and Debrue M. Peritoneal sarcomatosis associated with telemetry Implants in Sprague Dawley CD rats. Toxicol Pathol. 40(1): 113-121. 2012.

Slotwiner P, Song SK, and Anderson PJ. Spheromembraneous degeneration of muscle induced by vincristine. Arch Neurol. 15: 172-176. 1966.

Stefanski SA, Elwell MR, and Yoshitomi K. Malignant hibernoma in a Fischer 344 rat. Lab Anim Sci. 37: 347-350. 1987.

Stewart HL. Tumours of the soft tissues. Pathology of Tumours in Laboratory Animals. Tumours of the Mouse. V. S. Turusov. Lyon. IARC. 2: 487-525. 1979.

Sundberg JP, Adkison DK, and Bedigian HG. Skeletal muscle rhabdomyosarcomas in inbred laboratory mice. Vet Pathol. 28: 200-206. 1991.

Taguchi S, Kuriwaki K, Souda M, Funato M, Ninomiya K, Umekita Y, and Yoshida H. Induction of sarcomas by a single subcutaneous injection of 7,12-dimethylbenz a anthracene into neonatal male Sprague-Dawley rats:
Histopathological and immunohistochemical analyses. Toxicol Pathol. 34(4): 336-347. 2006.

Takagi A, Hirose A, Nishimura T, Fukumori N, Ogata A, Ohashi N, Kitajima $\mathrm{S}$, and Kanno J. Induction of mesothelioma in $\mathrm{p} 53+/-$ mouse by intraperitoneal application of multi-wall carbon nanotube. $J$ Toxicol Sci. 33(1): 105-116. 2008.

Thuilliez C, Dorso L, Howroyd P, Gould S, Chanut F, and Burnett R. Histopathological lesions following intramuscular administration of saline in laboratory rodents and rabbits. Exp Toxicol Pathol. 61(1): 13-21. 2009.

Tillmann T, Kamino K, Dasenbrock C, Ernst H, Kohler M, Morawietz G, Campo E, Cardesa A, Tomatis L, and Mohr U. Subcutaneous soft tissue tumours at the site of implanted microchips in mice. Exp Toxicol Pathol. 49(3-4): 197-200. 1997.

Tos APD. Classification of pleomorphic sarcomas: where are we now? Histopathol. 48(1): 51-62. 2006.

Travis WD, Brambilla E, Müller-Hermelink HK, and Harris CC. (2004). Pathology and Genetics of Tumours of the Lung, Pleura, Thymus and Heart. Lyon, IARC Press.

Tsuchiya T, Takahashi K, Takeya M, Hosokawa Y, Hattori T, and Takagi K. Immunohistochemical, quantitative immunoelectron microscopic, and DNA cytofluorometric characterization of chemically induced rat malignant fibrous histiocytoma. Am J Pathol. 143: 431-445. 1993.

Valtieri M, and Sorrentino A. The mesenchymal stromal cell contribution to homeostasis. J Cell Physiol. 217(2): 296-300. 2008.

Verdier F, Burnett R, Michelet-Habchi C, Moretto P, Fievet-Groyne F, and Sauzeat E. Aluminium assay and evaluation of the local reaction at several time points after intramuscular administration of aluminium containing vaccines in the Cynomolgus monkey. Vaccine. 23(11): 1359-1367. 2005.

von Ruhland CJ, Campbell L, Gumbleton M, Jasani B, and Newman GR. Immunolocalization of caveolin-1 in rat and human mesothelium. $J$ Histochem Cytochem. 52(11): 1415-1425. 2004.

Waites CR, Dominick MA, Sanderson TP, and Schilling BE. Nonclinical safety evaluation of muraglitazar, a novel PPARalpha/gamma agonist. Toxicol Sci. 100(1): 248-258. 2007.

Weisberg SP, McCann D, Desai M, Rosenbaum M, Leibel RL, and Ferrante AW Jr. Obesity is associated with macrophage accumulation in adipose tissue. J Clin Invest. 112(12): 1796-1808. 2003.

Wellen KE, and Hotamisligil GS. Obesity-induced inflammatory changes in adipose tissue. J Clin Invest. 112(12): 1785-1788. 2003.

Westwood FR, Bigley A, Randall K, Marsden AM, and Scott RC. Statininduced muscle necrosis in the rat: Distribution, development, and fibre selectivity. Toxicol Pathol. 33(2): 246-257. 2005.

Westwood FR, Duffy PA, Malpass DA, Jones HB, and Topham JC. Disturbance of macrophage and monocyte function in the dog by a thromboxane receptor antagonist; ICI 185,282. Toxicol Pathol. 23: 373-384. 1995.

Westwood FR, Scott RC, Marsden AM, Bigley A, and Randall K. Rosuvastatin: Characterization of induced myopathy in the rat. Toxicologic $\mathrm{Pa}$ thology. 36(2): 345-352. 2008.

Williams DF. Review. Tissue-biomaterial interactions. $J$ Materials Sci. 22: 3421-3445. 1987.

Wright JA, Goonetilleke URP, Waghe M, Horne M, and Stewart MG. An immunohistochemical study of spontaneous histiocytic tumours in the rat. Journal of Comparative Pathology. 104: 223-232. 1991.

Xu H, Barnes GT, Yang Q, Tan G, Yang D, Chou CJ, Sole J, Nichols A, Ross JS, Tartaglia LA, and Chen H. Chronic inflammation in fat plays a crucial role in the development of obesity-related insulin resistance. $J$ Clin Invest. 112: $1821-1830.2003$ 